Supporting Information

\title{
A Facile, Versatile, and Highly Efficient Strategy for Peroxynitrite Bioimaging Enabled by Formamide Deformylation
}

Xilei Xie, ${ }^{*}{ }^{\dagger}$ Guangzhao Liu, ${ }^{\dagger}$ Xingxing Su, Yong Li, Yawen Liu, Xiaoyun Jiao, Xu Wang,* and Bo Tang*

College of Chemistry, Chemical Engineering and Materials Science, Key Laboratory of Molecular and Nano Probes, Ministry of Education, Collaborative Innovation Center of Functionalized Probes for Chemical Imaging in Universities of Shandong, Shandong Normal University, Jinan 250014, People's Republic of China

E-mail: xiexilei@sdnu.edu.cn; wangxu@sdnu.edu.cn; tangb@sdnu.edu.cn.

${ }^{\dagger}$ These authors contributed equally to this work. 


\section{Contents}

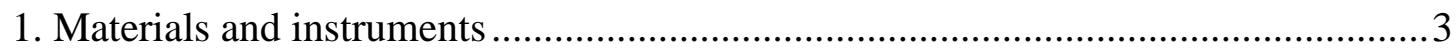

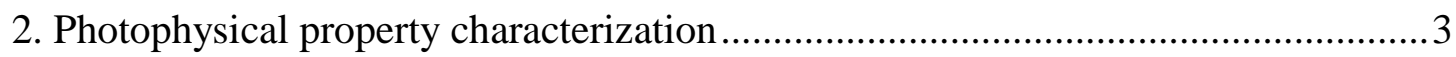

3. Fluorescence responses of FPP-Yellow, FPP-Ac and FPP-TFA ..............................5

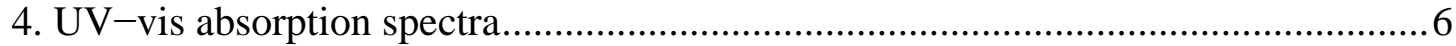

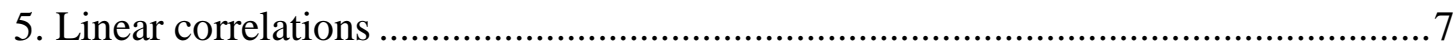

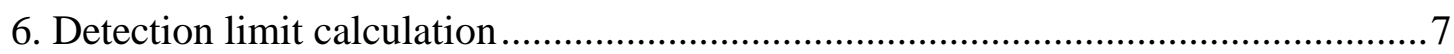

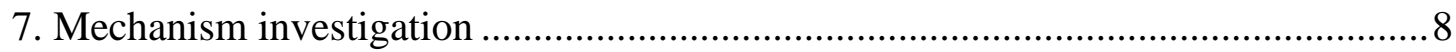

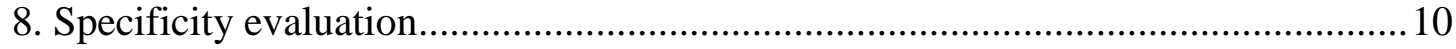

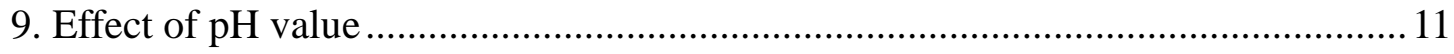

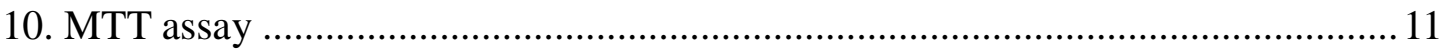

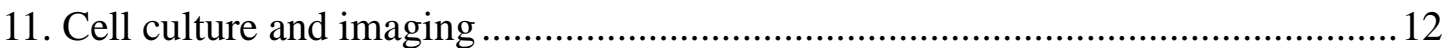

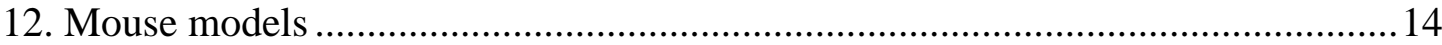

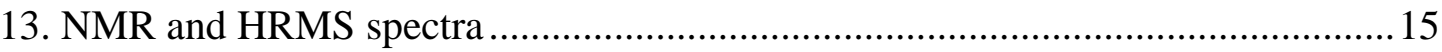




\section{Materials and instruments}

Reagents and solvents were acquired from commercial sources, and the solvents were distilled or purified before use if necessary. Phosphate buffers and universal buffer solutions were prepared using distilled water. Peroxynitrite $\left(\mathrm{ONOO}^{-}\right)$solution was prepared according to the previous method. Briefly, a mixture of sodium nitrite $(0.6 \mathrm{M})$ and hydrogen peroxide $(0.7 \mathrm{M})$ was acidified with hydrochloric acid $(0.6 \mathrm{M})$, and sodium hydroxide $(1.5 \mathrm{M})$ was added within $1-2 \mathrm{~s}$ to make the solution alkaline. The $\mathrm{ONOO}^{-}$concentration was estimated by using an extinction coefficient of 1670 $\mathrm{M}^{-1} \mathrm{~cm}^{-1}$ at $302 \mathrm{~nm} \cdot \mathrm{C}_{\mathrm{ONOO}}{ }^{-}=\mathrm{Abs}_{302 \mathrm{~nm}} / 1.67(\mathrm{mM})$. Hydrogen peroxide $\left(\mathrm{H}_{2} \mathrm{O}_{2}\right)$, hypochlorite $\left(\mathrm{ClO}^{-}\right)$and tert-butyl hydroperoxide $(t-\mathrm{BuOOH})$ were delivered from commercial aqueous solutions respectively. Nitric oxide (NO) was used from a stock solution prepared by sodium nitroprusside. Singlet oxygen $\left({ }^{1} \mathrm{O}_{2}\right)$ was generated in situ by addition of the $\mathrm{H}_{2} \mathrm{O}_{2}$ stock solution into a solution containing 10 equiv. of $\mathrm{HClO}$. Superoxide solution $\left(\mathrm{O}_{2}{ }^{-}\right)$was prepared by adding $\mathrm{KO}_{2}$ to dry dimethyl sulfoxide (DMSO) and stirring vigorously for $10 \mathrm{~min}$. Hydroxyl radicals $\left({ }^{\circ} \mathrm{OH}\right)$ was generated in situ by reaction of $\mathrm{Fe}^{2+}$ with $\mathrm{H}_{2} \mathrm{O}_{2}$.

NMR spectroscopic characterization was taken on a Bruker Advance $400 \mathrm{MHz}$ spectrometer. HRMS spectra were obtained by a Bruker MaXis UHR-TOF instrument. HPLC analysis was carried out on a Shimadzu LC-16 system equipped with SPD-16 UV-vis detector. Fluorescence measurements were done using a FLS-980 fluorospectrometer from Edinburgh Instruments. One-photon and two-photon fluorescence imaging of live cells and tissues were all performed on a Zeiss LSM 880 confocal laser scanning microscope. Flow cytometry was accomplished on an Amnis ImageStream ${ }^{\mathrm{X}}$ multispectral imaging flow cytometer.

\section{Photophysical property characterization}

The probes were dissolved in DMSO to produce $5 \mathrm{mM}$ stock solutions, which were diluted to $50 \mu \mathrm{M}$ as the testing solutions with phosphate buffer (50 mM, pH 7.4). To test the UV-vis absorption spectra of the probes in the absence and presence of 
$\mathrm{ONOO}^{-}$, aliquots of probe stock solutions were diluted with phosphate buffer $(50 \mathrm{mM}$, $\mathrm{pH}$ 7.4) and treated with $\mathrm{ONOO}^{-}$to make sure both probes and $\mathrm{ONOO}^{-}$were kept at desired final concentrations. The testing solutions were quickly and vigorously shaken. The absorption spectra were recorded after incubation at $37{ }^{\circ} \mathrm{C}$ for $10 \mathrm{~min}$.

The probes were dissolved in DMSO to produce $500 \mu \mathrm{M}$ stock solutions, which were diluted to $2 \mu \mathrm{M}$ as the testing solutions with phosphate buffer (50 mM, pH 7.4). To test the fluorescence responses of the probes towards $\mathrm{ONOO}^{-}$or other analytes, aliquots of probe stock solutions were diluted with phosphate buffer (50 mM, pH 7.4) and treated with analytes to make sure both probes and analytes were kept at desired final concentrations. The testing solutions were quickly and vigorously shaken. The fluorescence spectra were recorded immediately or after incubation at $37{ }^{\circ} \mathrm{C}$ for 10 $\min$.

To test the fluorescence responses of the probes towards $\mathrm{ONOO}^{-}$at different $\mathrm{pH}$ values, aliquots of probe stock solutions were diluted with universal buffer solution (0.1 M citric acid, $0.1 \mathrm{M} \mathrm{KH}_{2} \mathrm{PO}_{4}, 0.1 \mathrm{M} \mathrm{Na}_{2} \mathrm{~B}_{4} \mathrm{O}_{7}, 0.1 \mathrm{M}$ Tris, and $0.1 \mathrm{M} \mathrm{KCl}$ ) of specified $\mathrm{pH}$ value and treated with $\mathrm{ONOO}^{-}$to make sure both probes and $\mathrm{ONOO}^{-}$ were kept at desired final concentrations. After quick and vigorous shaking, the fluorescence intensity was measured after incubation at $37^{\circ} \mathrm{C}$ for $10 \mathrm{~min}$. 


\section{Fluorescence responses of FPP-Yellow, FPP-Ac and FPP-TFA}

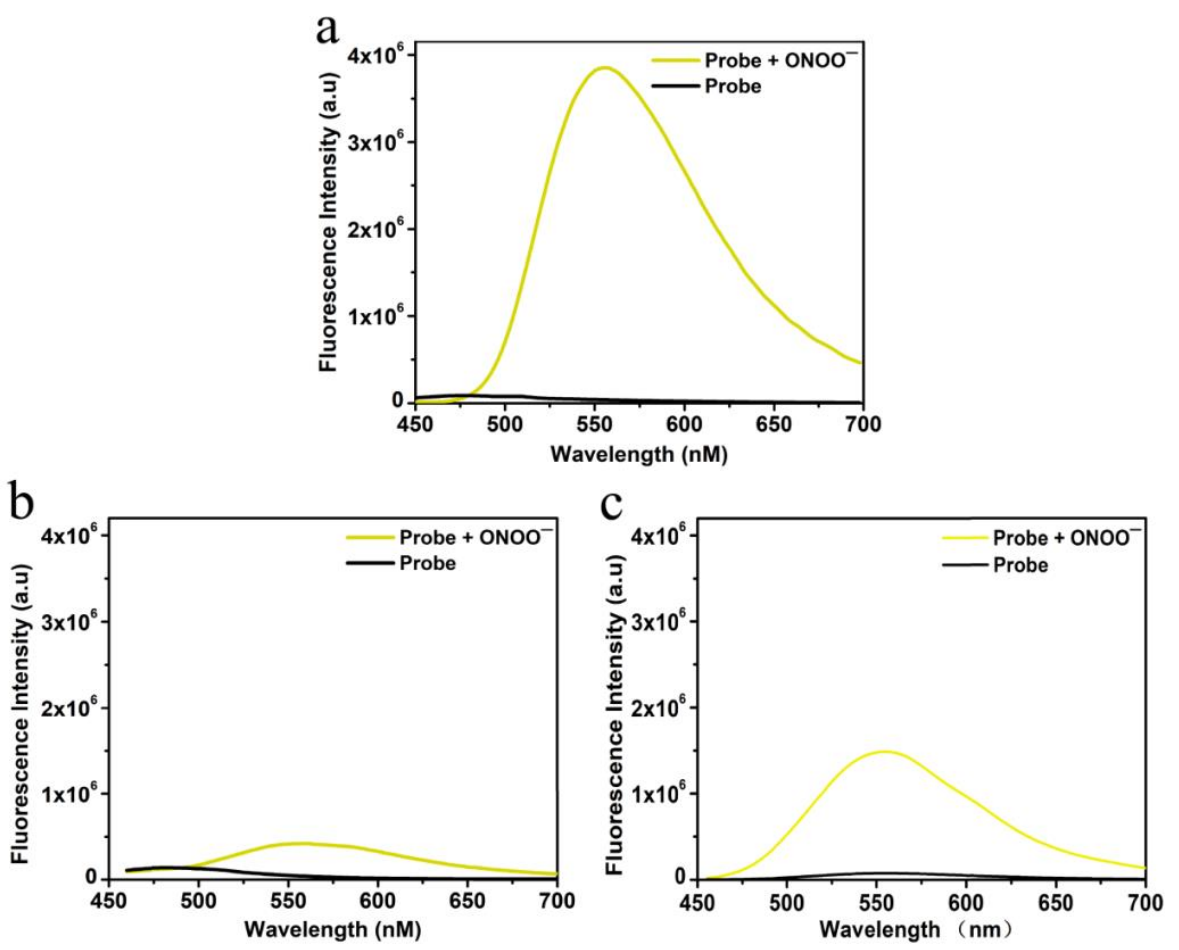

Figure S1. Fluorescence spectra of (a) FPP-Yellow, (b) FPP-Ac, and (c) FPP-TFA in the absence (black line) and presence (yellow line) of $10 \mu \mathrm{M} \mathrm{ONOO}^{-}$. The final concentration of the probes was $2 \mu \mathrm{M}$. Data were acquired in $50 \mathrm{mM}$ phosphate buffer (pH 7.4, 4\% DMSO) after incubation at $37{ }^{\circ} \mathrm{C}$ for $10 \min . \lambda_{\mathrm{ex}} / \lambda_{\mathrm{em}}=435 / 560 \mathrm{~nm}$. 


\section{UV-vis absorption spectra}
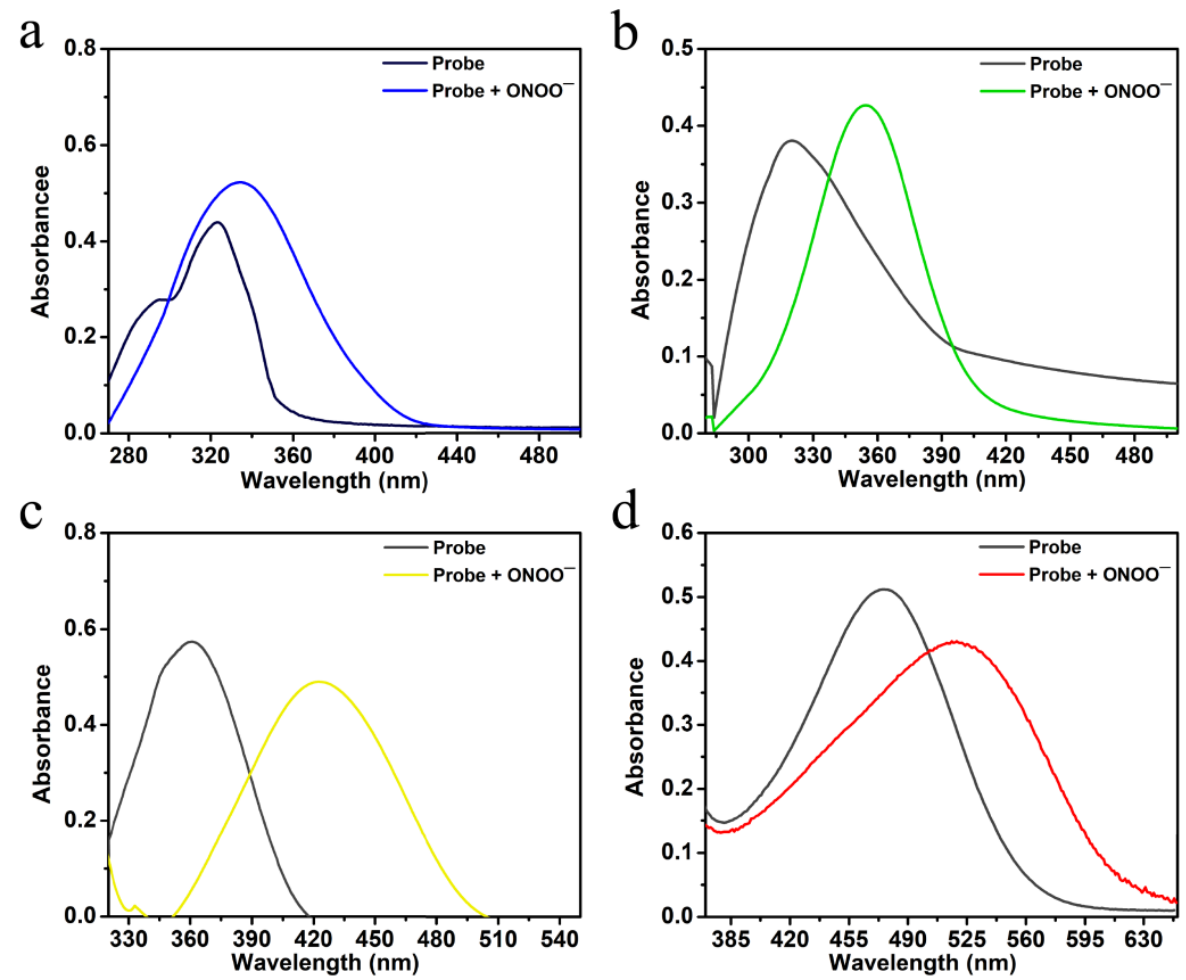

Figure S2. UV-vis absorption spectra of (a) FPP-Blue, (b) FPP-Green, (c) FPP-Yellow, and (d) FPP-Red in the absence (black line) and presence (colored line) of $\mathrm{ONOO}^{-}$. The final concentration of the probes was $50 \mu \mathrm{M}$, and $\mathrm{ONOO}^{-}$ concentrations were $250 \mu \mathrm{M}(\mathrm{a}-\mathrm{c})$ and $100 \mu \mathrm{M}(\mathrm{d})$, respectively. Data were acquired in $50 \mathrm{mM}$ phosphate buffer (pH 7.4, 1\% DMSO) after incubation at $37^{\circ} \mathrm{C}$ for $10 \mathrm{~min}$. 


\section{Linear correlations}
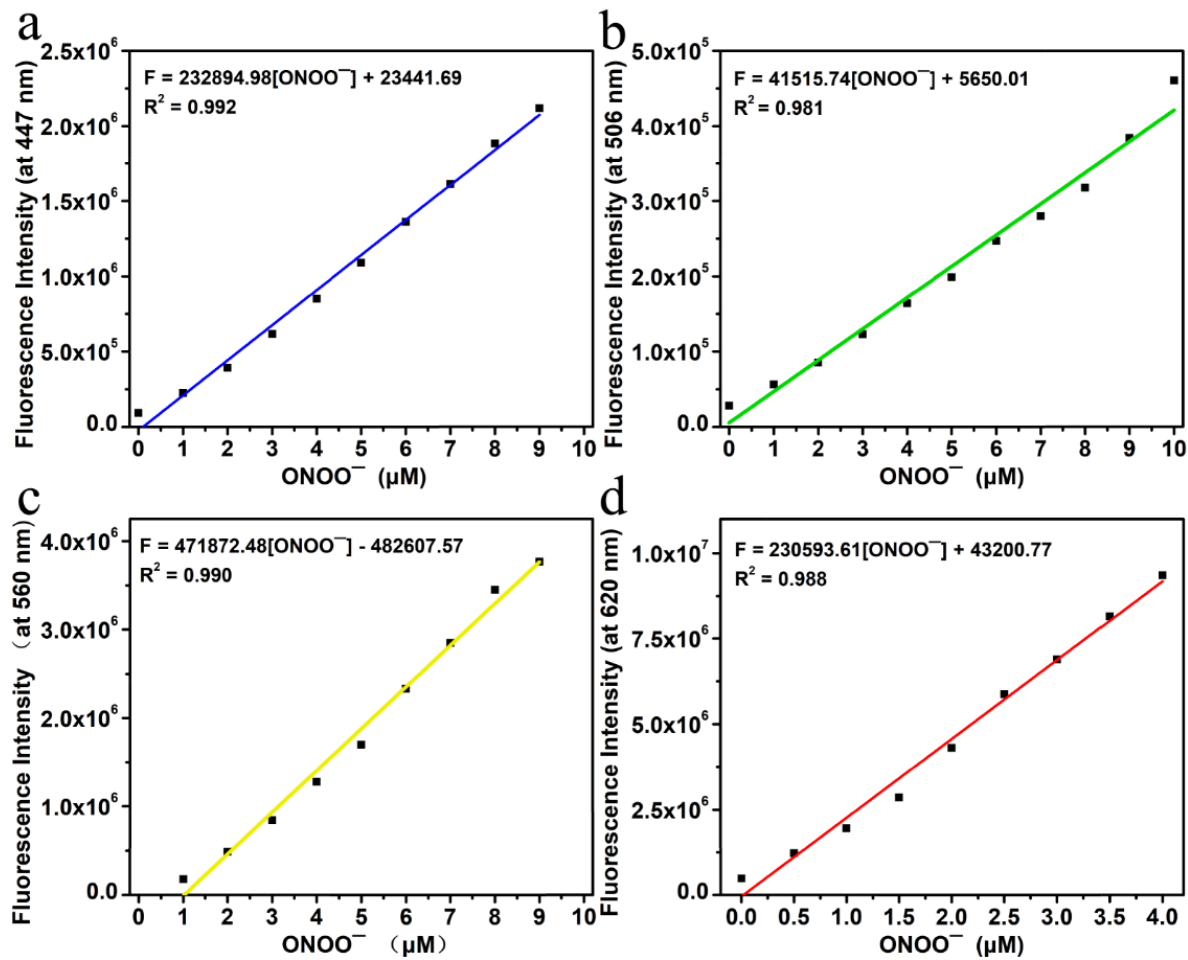

Figure S3. Linear correlations between $\mathrm{ONOO}^{-}$concentration and the fluorescence intensity at the emission maxima of (a) FPP-Blue, (b) FPP-Green, (c) FPP-Yellow, and (d) FPP-Red. The final concentration of the probes was $2 \mu \mathrm{M}$. Fluorescence intensity was acquired in $50 \mathrm{mM}$ phosphate buffer ( $\mathrm{pH} 7.4$, 4\% DMSO) immediately after solution preparation with excitation at (a) 375, (b) 385, (c) 435, and (d) $530 \mathrm{~nm}$, respectively.

\section{Detection limit calculation}

The detection limit (LOD) was calculated as follows: $\mathrm{LOD}=3 \sigma / k, \sigma=\sqrt{\frac{\sum\left(\bar{\chi}-\chi_{i}\right)^{2}}{n-1}}$, where $\sigma$ is the standard deviation of the blank solution, $\bar{x}$ is the mean of the blank measures, $x_{i}$ is the value of blank measures, $n$ is the number of tested blank measures ( $n=11)$, and $k$ is the slope of the linear calibration plot between the fluorescence intensity and $\mathrm{ONOO}^{-}$concentration. 


\section{Mechanism investigation}
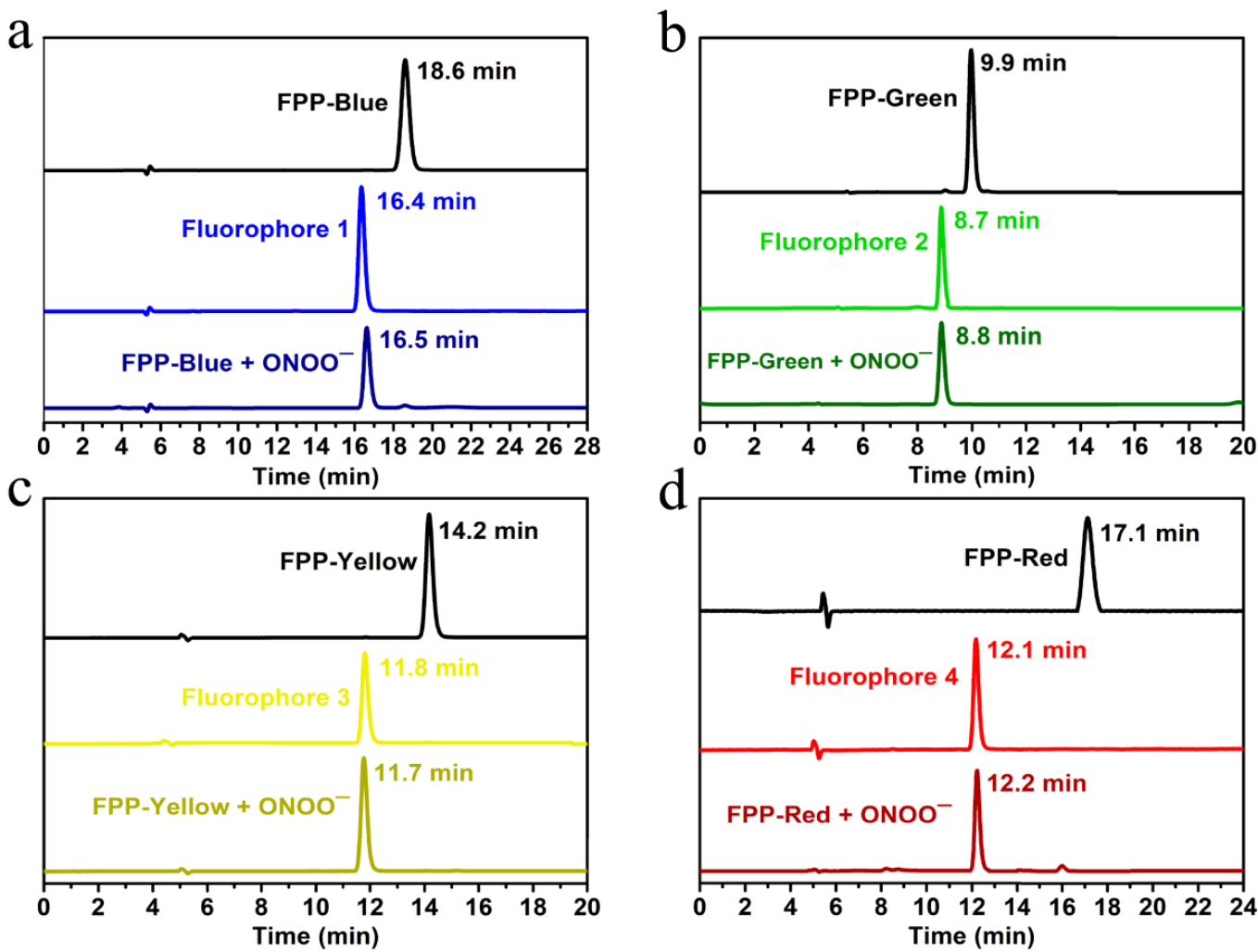

Figure S4. HPLC analysis of the fluorescent products of (a) FPP-Blue, (b) FPP-Green,

(c) FPP-Yellow, and (d) FPP-Red incubated with 5 equiv. $(a-c)$ or 2 equiv. (d) of $\mathrm{ONOO}^{-}$. HPLC analysis was carried out on a Shimadzu LC-16 system equipped with SPD-16 UV-vis detector. Chromatographic separation was performed on a ZORBAX Eclipse Plus C18 reversed-phase column $(4.6 \times 250 \mathrm{~mm}, 5 \mu \mathrm{m})$. The mobile phase was a mixture of water and methanol delivered at a flow rate of $0.5 \mathrm{~mL} / \mathrm{min}$, and the volume ratio of water/methanol was (a) 55/45, (b) 10/90, (c) 20/80, or (d) 20/80. The detection wavelength was set at (a) 320, (b) 340, (c) 390, and (d) $510 \mathrm{~nm}$, respectively. 

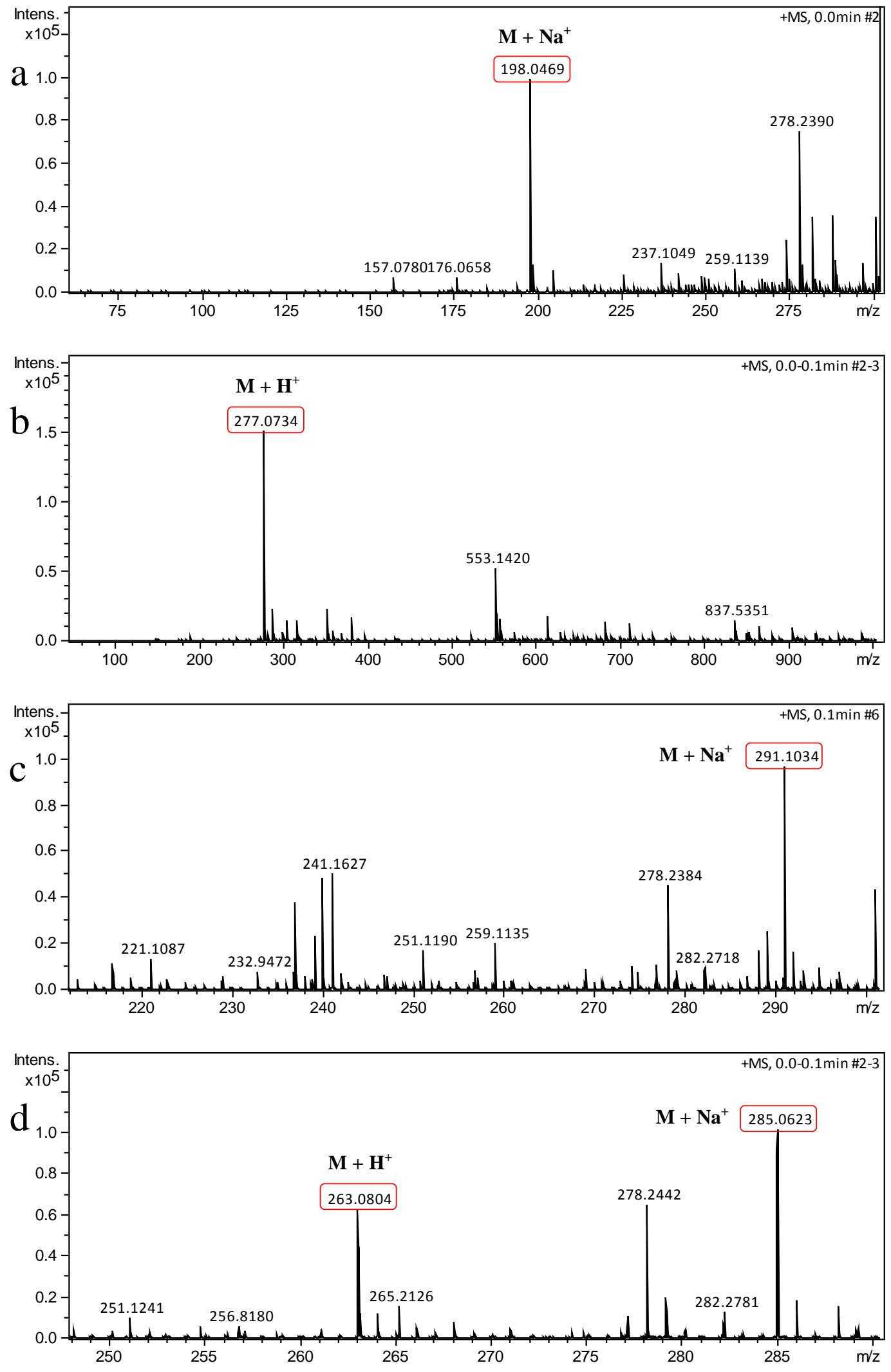

Figure S5. HRMS spectral analysis of the fluorescent products of (a) FPP-Blue, (b) FPP-Green, (c) FPP-Yellow, and (d) FPP-Red incubated with 5 equiv. (a-c) or 2 equiv. (d) of $\mathrm{ONOO}^{-}$. 


\section{Specificity evaluation}
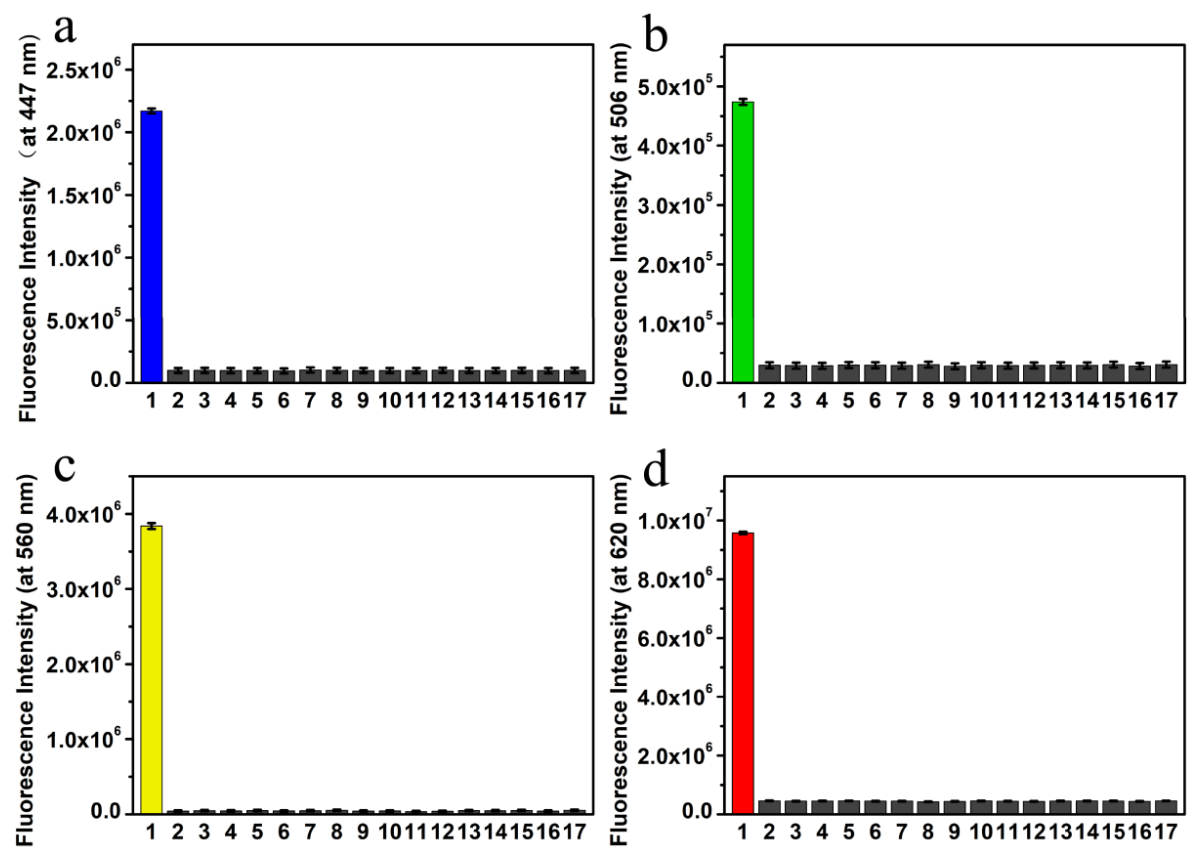

Figure S6. Fluorescence responses of (a) FPP-Blue, (b) FPP-Green, (c) FPP-Yellow, and (d) FPP-Red in the presence of $100 \mu \mathrm{M}$ analytes unless otherwise noted: (1) ONOO ${ }^{-}$; (2) blank; (3) $\mathrm{NO}_{3}^{-}$; (4) $\mathrm{NO}_{2}^{-}$; (5) $\mathrm{CH}_{3} \mathrm{COO}^{-}$; (6) $\mathrm{SO}_{4}{ }^{2-}$; (7) $\mathrm{SO}_{3}{ }^{2-}$; (8) $\mathrm{CO}_{3}{ }^{2-}$; (9) $\mathrm{PO}_{4}{ }^{3-}$; (10) $\mathrm{Na}^{+}$; (11) $\mathrm{K}^{+}$; (12) $\mathrm{Ca}^{2+}$; (13) $\mathrm{Mg}^{2+}$; (14) $\mathrm{Zn}^{2+}$; (15) $\mathrm{Cu}^{2+}$; (16) $\mathrm{Fe}^{2+}$; and (17) $\mathrm{Fe}^{3+}$. $\mathrm{ONOO}^{-}$concentrations were $10 \mu \mathrm{M}(\mathrm{a}-\mathrm{c})$ and $4 \mu \mathrm{M}$ (d), respectively. The final concentration of the probes was $2 \mu \mathrm{M}$. Fluorescence intensity

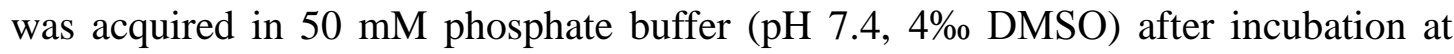
$37{ }^{\circ} \mathrm{C}$ for $10 \mathrm{~min}$, with excitation at (a) 375, (b) 385, (c) 435, and (d) $530 \mathrm{~nm}$, respectively. 


\section{Effect of $\mathrm{pH}$ value}
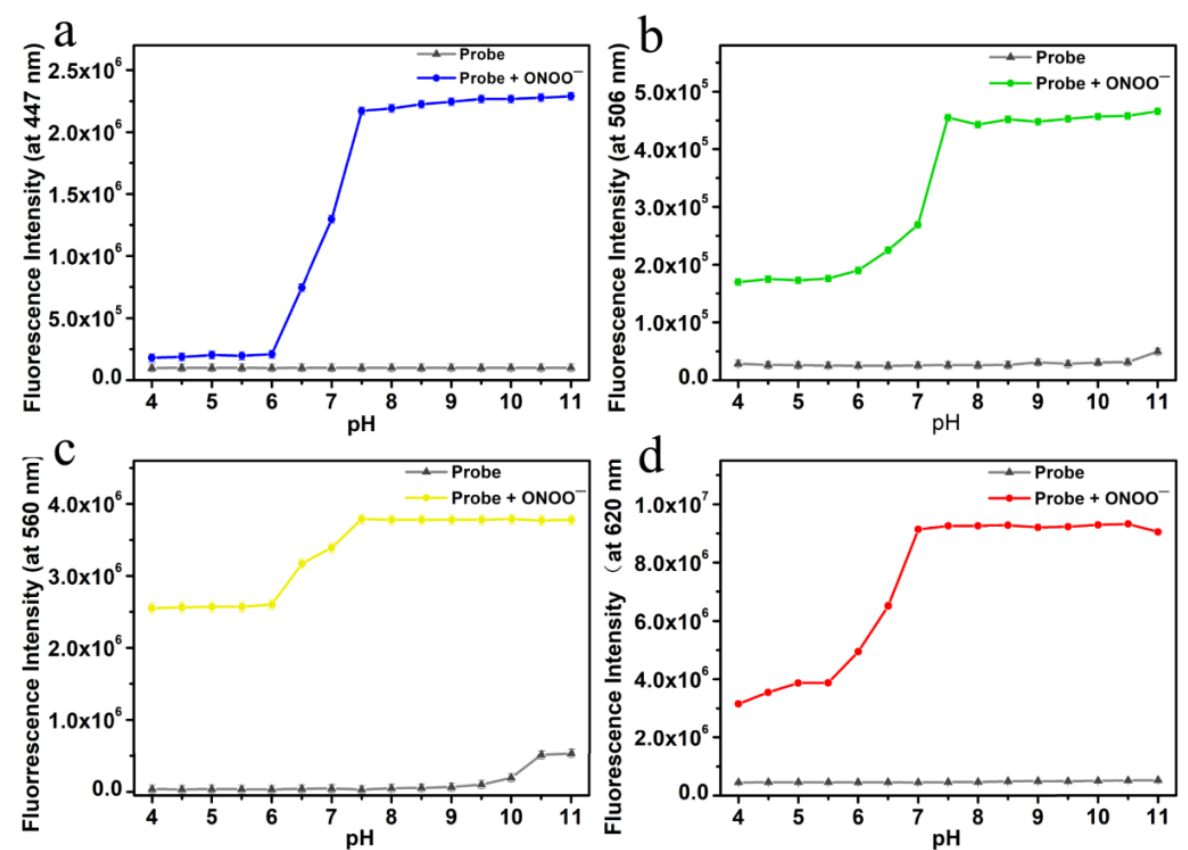

Figure S7. Fluorescence responses of (a) FPP-Blue, (b) FPP-Green, (c) FPP-Yellow, and (d) FPP-Red in the absence and presence of $\mathrm{ONOO}^{-}$in the $\mathrm{pH}$ range 4.0-11.0. $\mathrm{ONOO}^{-}$concentrations were $10 \mu \mathrm{M}(\mathrm{a}-\mathrm{c})$ and $4 \mu \mathrm{M}(\mathrm{d})$, respectively. The final concentration of the probes was $2 \mu \mathrm{M}$. Fluorescence intensity was acquired in universal buffer solution ( $0.1 \mathrm{M}$ citric acid, $0.1 \mathrm{M} \mathrm{KH}_{2} \mathrm{PO}_{4}, 0.1 \mathrm{M} \mathrm{Na}_{2} \mathrm{~B}_{4} \mathrm{O}_{7}, 0.1 \mathrm{M}$ Tris, and $0.1 \mathrm{M} \mathrm{KCl}$ ) containing $4 \%$ DMSO after incubation at $37{ }^{\circ} \mathrm{C}$ for $10 \mathrm{~min}$, with excitation at (a) 375, (b) 385, (c) 435, and (d) $530 \mathrm{~nm}$, respectively.

\section{MTT assay}

HepG2 cells were seeded into a 96 -well microtiter plate at $37{ }^{\circ} \mathrm{C}$ in a $5 \% \mathrm{CO}_{2} / 95 \%$ air incubator for $24 \mathrm{~h}$. The cells were incubated for an additional $12 \mathrm{~h}$ with different concentrations of tested probe $(0,1,10,20,50$, and $100 \mu \mathrm{M})$, respectively. Then the cells were washed with PBS three times. Subsequently, MTT solution (200 $\mu$ L, 0.5 $\mathrm{mg} / \mathrm{mL}$ ) was added to each well and the cells were incubated at $37{ }^{\circ} \mathrm{C}$. After $4 \mathrm{~h}$, the remaining MTT was removed, and the formazan crystals were dissolved in $200 \mu \mathrm{L}$ of DMSO with gentle agitation for $5 \mathrm{~min}$. The absorbance at $490 \mathrm{~nm}$ was measured using a TRITURUS microplate reader. 

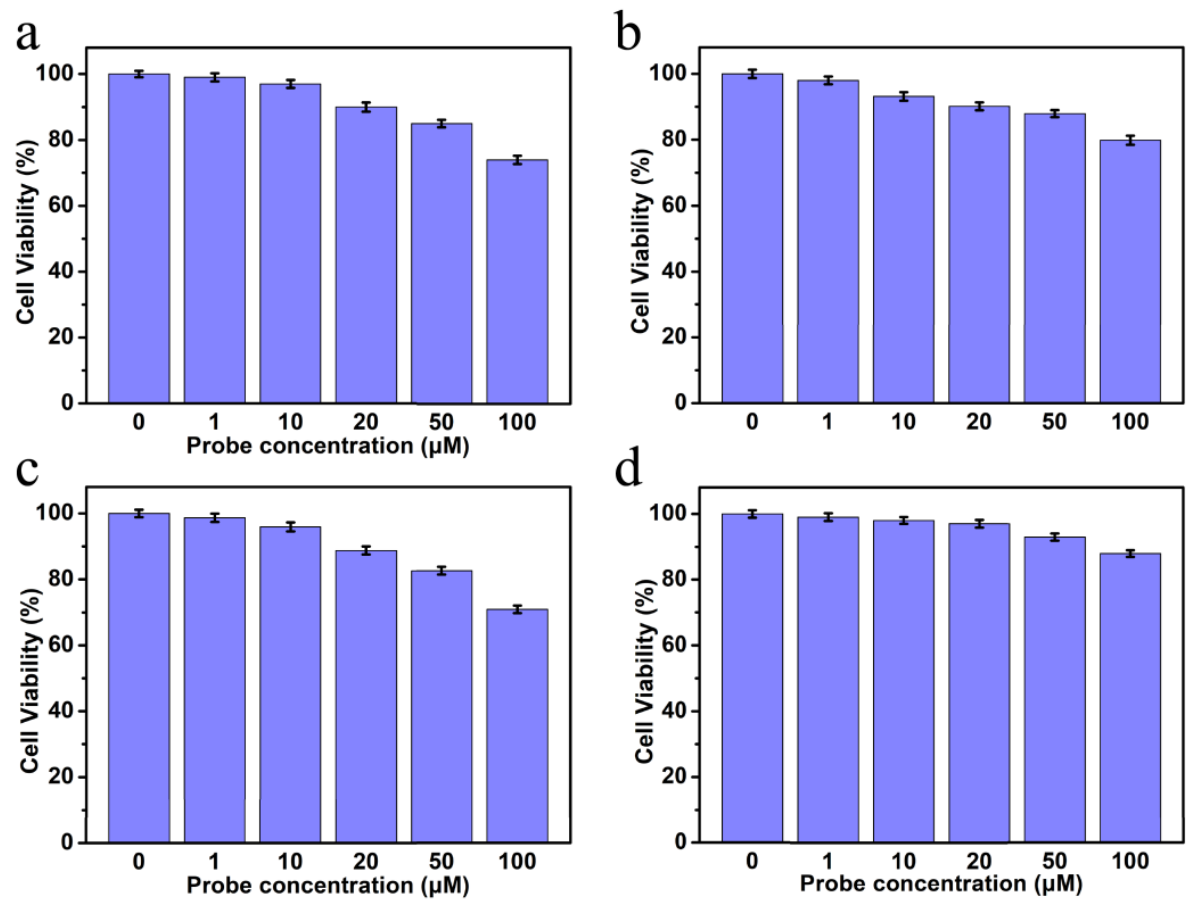

Figure S8. MTT assays of HepG2 cells with different concentrations of (a) FPP-Blue, (b) FPP-Green, (c) FPP-Yellow, and (d) FPP-Red. The IC $_{50}$ values were calculated to be $124,168,146$, and $190 \mu \mathrm{M}$, respectively.

\section{Cell culture and imaging}

HepG2 and A549 cells were cultured in high-glucose DMEM supplemented with $10 \%$ fetal bovine serum, $1 \%$ penicillin, and $1 \%$ streptomycin at $37{ }^{\circ} \mathrm{C}$ in a $5 \% \mathrm{CO}_{2}$ 195\% air incubator (MCO-5AC, Sanyo). One day before imaging, the cells were detached and replanted on glass-bottomed dishes. Cell imaging was performed on a Zeiss LSM 880 confocal microscope.

For monitoring of $\mathrm{ONOO}^{-}$released from SIN-1 in live cells, HepG2 cells were pretreated with SIN-1 (500 $\mu \mathrm{M})$ for 30 min before being washed three times with PBS; then, they were incubated with the probe $(5 \mu \mathrm{M})$ for 20 min before being rinsed with PBS. For the scavenging assay, the cells were treated with uric acid $(100 \mu \mathrm{M}) 3 \mathrm{~h}$ in advance.

For monitoring of $\mathrm{ONOO}^{-}$during paraquat poisoning, HepG2 and A549 cells were pretreated with the corresponding concentration $(0,50,100,150,200$, and $200 \mu \mathrm{M})$ of paraquat for $45 \mathrm{~min}$ before being washed three times with PBS; then, they were 
incubated with FPP-Yellow $(5 \mu \mathrm{M})$ for 20 min before being rinsed with PBS. For the scavenging assay, the cells were treated with uric acid $(100 \mu \mathrm{M}) 3 \mathrm{~h}$ in advance. For the inhibiting groups, the cells were treated with aminoguanidine $(500 \mu \mathrm{M})$ or apocynin $(500 \mu \mathrm{M}) 14 \mathrm{~h}$ in advance.

For flow cytometry, after treatment, HepG2 cells were washed three times with PBS. Each group of cells was trypsinized and centrifuged to collect the cell precipitate and then resuspended in PBS solution. The flow cytometry was performed on an Amnis ImageStream ${ }^{\mathrm{X}}$ multispectral imaging flow cytometer, and the results were analyzed using the Amnis IDEAS ${ }^{\circledR}$ image analysis software.
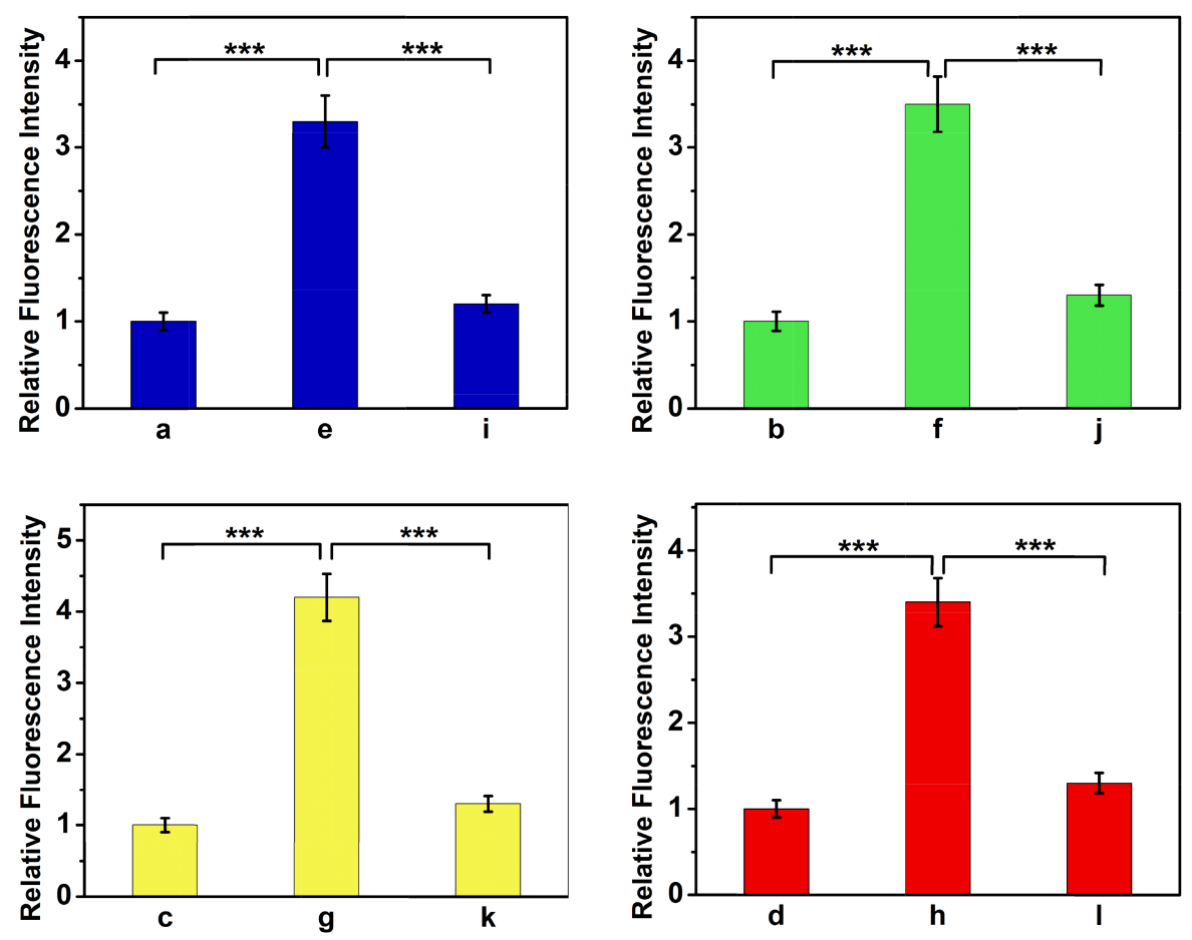

Figure S9. Relative mean fluorescence intensities in cells of Figure 5 were quantified. The values are the mean \pm sd for $n=3: * * p<0.01, * * * p<0.001$. 

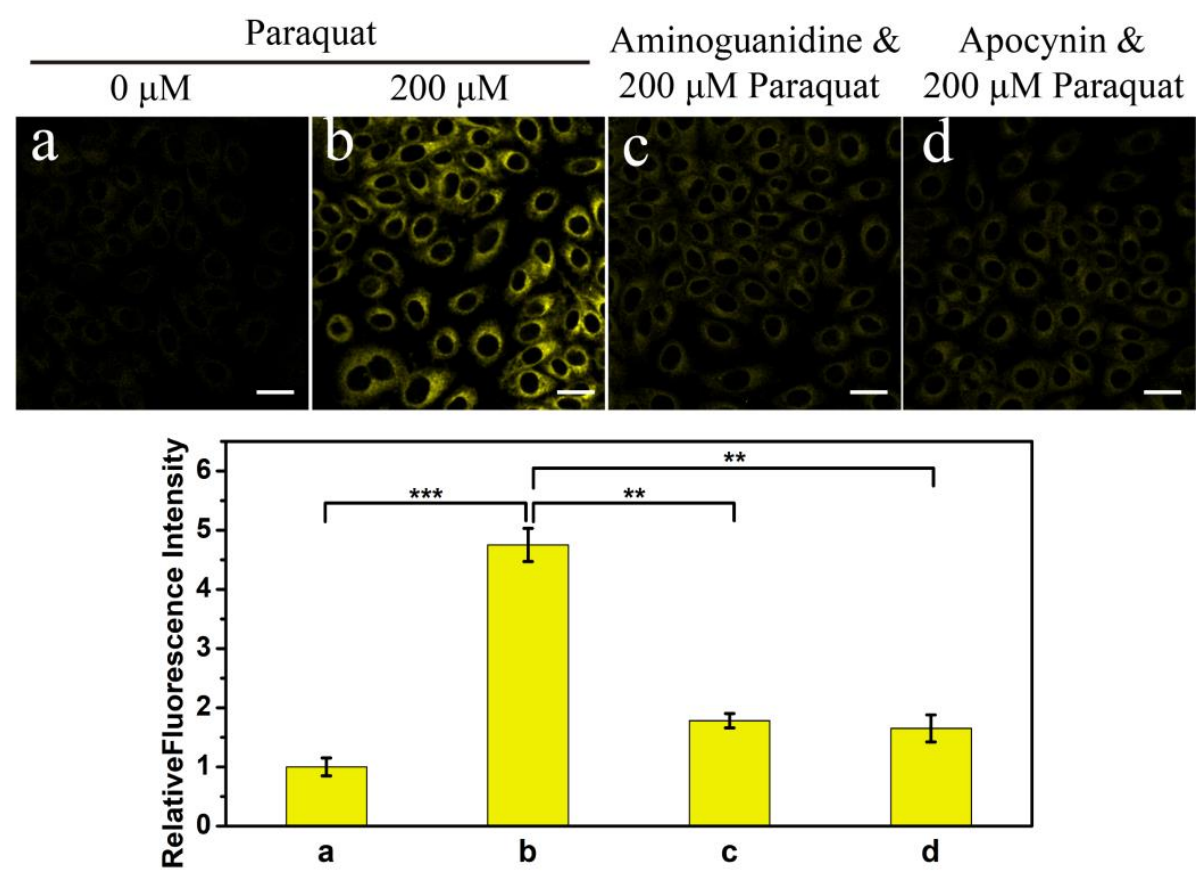

Figure S10. (top) Fluorescence images of FPP-Yellow in response to $\mathrm{ONOO}^{-}$in HepG2 cells after paraquat treatment. Cells were treated with (a) $0 \mu \mathrm{M}$, (b) $200 \mu \mathrm{M}$, (c) $200 \mu \mathrm{M}$, or (d) $200 \mu \mathrm{M}$ paraquat, followed by incubation with $5 \mu \mathrm{M}$ FPP-Yellow. Cells in inhibiting groups were pretreated with $500 \mu \mathrm{M}$ aminoguanidine (c) or 500 $\mu \mathrm{M}$ apocynin (d) in advance. Images were obtained by collecting the emissions at 520-600 nm upon two-photon excitation at $800 \mathrm{~nm}$. Scale bar: $20 \mu \mathrm{m}$. (bottom) Relative mean fluorescence intensities of cells in $(a-d)$ were quantified. The values are the mean $\pm \operatorname{sd}$ for $n=3: * * p<0.01, * * * p<0.001$.

\section{Mouse models}

All animal experiments were approved by the Animal Care and Use Committee of Shandong Normal University, and were performed in compliance with the Animal Management Rules of the Ministry of Health of the People's Republic of China and the Guidelines for the Care and Use of Laboratory Animals of Shandong Normal University.

Kunming mice were fasted for $12 \mathrm{~h}$ to avoid possible food fluorescence interference to the dye fluorescence before imaging. The mice were randomly divided into the control group, the treated group, and the scavenging group. The mice were intraperitoneally injected with the corresponding dosage of paraquat $(0,50$, and 50 
$\mathrm{mg} / \mathrm{kg}, 200 \mu \mathrm{L})$ and then injected with FPP-Yellow $(50 \mu \mathrm{M}, 100 \mu \mathrm{L})$ through the tail vein. The mice of the scavenging group were pretreated with uric acid $(100 \mathrm{mg} / \mathrm{kg}$, $200 \mu \mathrm{L}$ ) intraperitoneally before paraquat administration and probe loading. After anaesthesia, the hearts, livers, lungs, and kidneys were isolated and cut into slices for imaging. On the other hand, after anesthesia and a simple laparotomy, the livers were exposed and real-time imaged in live mice.

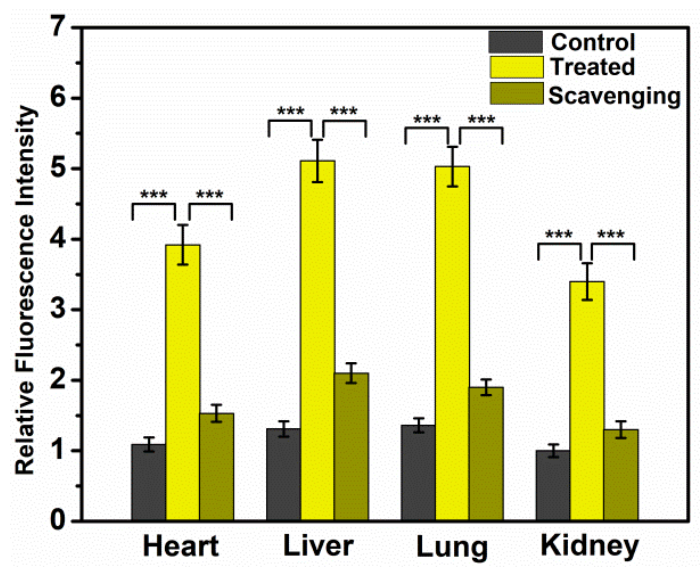

Figure S11. Relative mean fluorescence intensities in organs of mice in Figure 8a were quantified. The values are the mean \pm sd for $n=3: * * p<0.01, * * * p<0.001$.

\section{NMR and HRMS spectra}

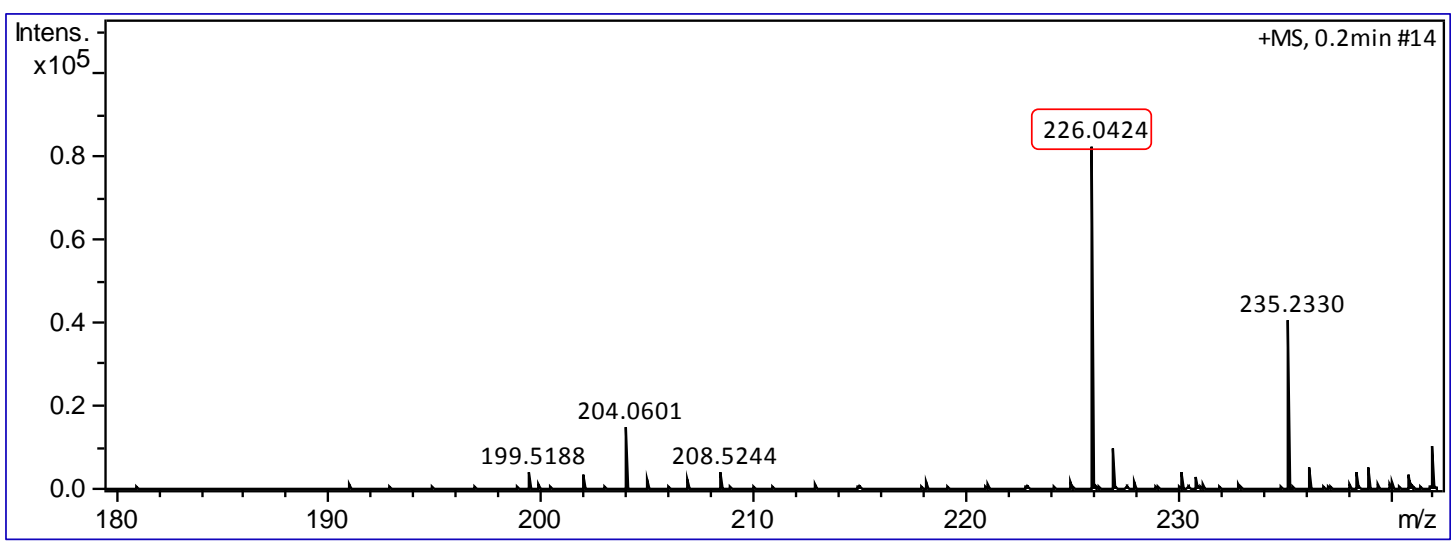

Figure S12. HRMS spectrum of FPP-Blue 


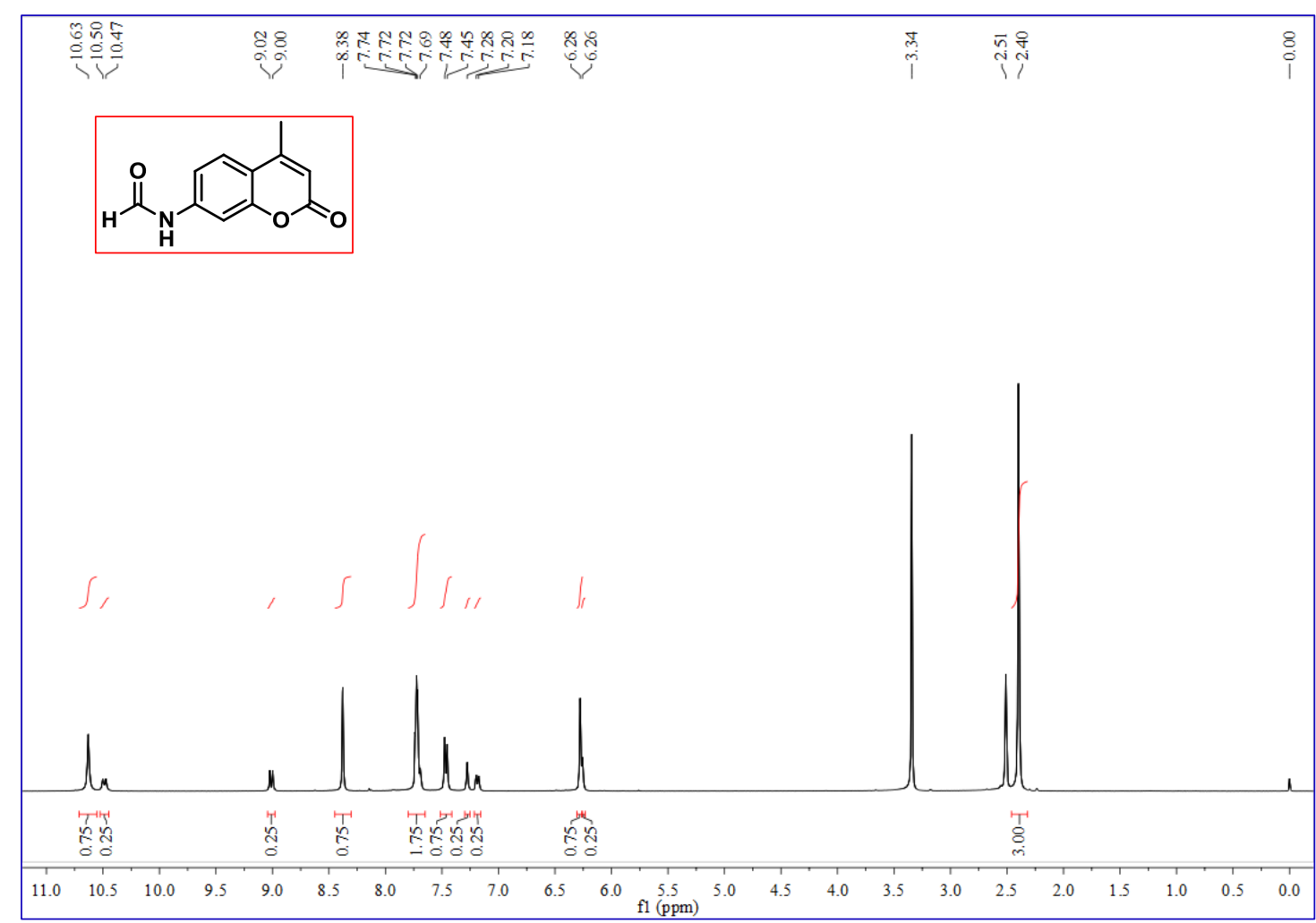

Figure S13. ${ }^{1} \mathrm{H}$ NMR spectrum of FPP-Blue

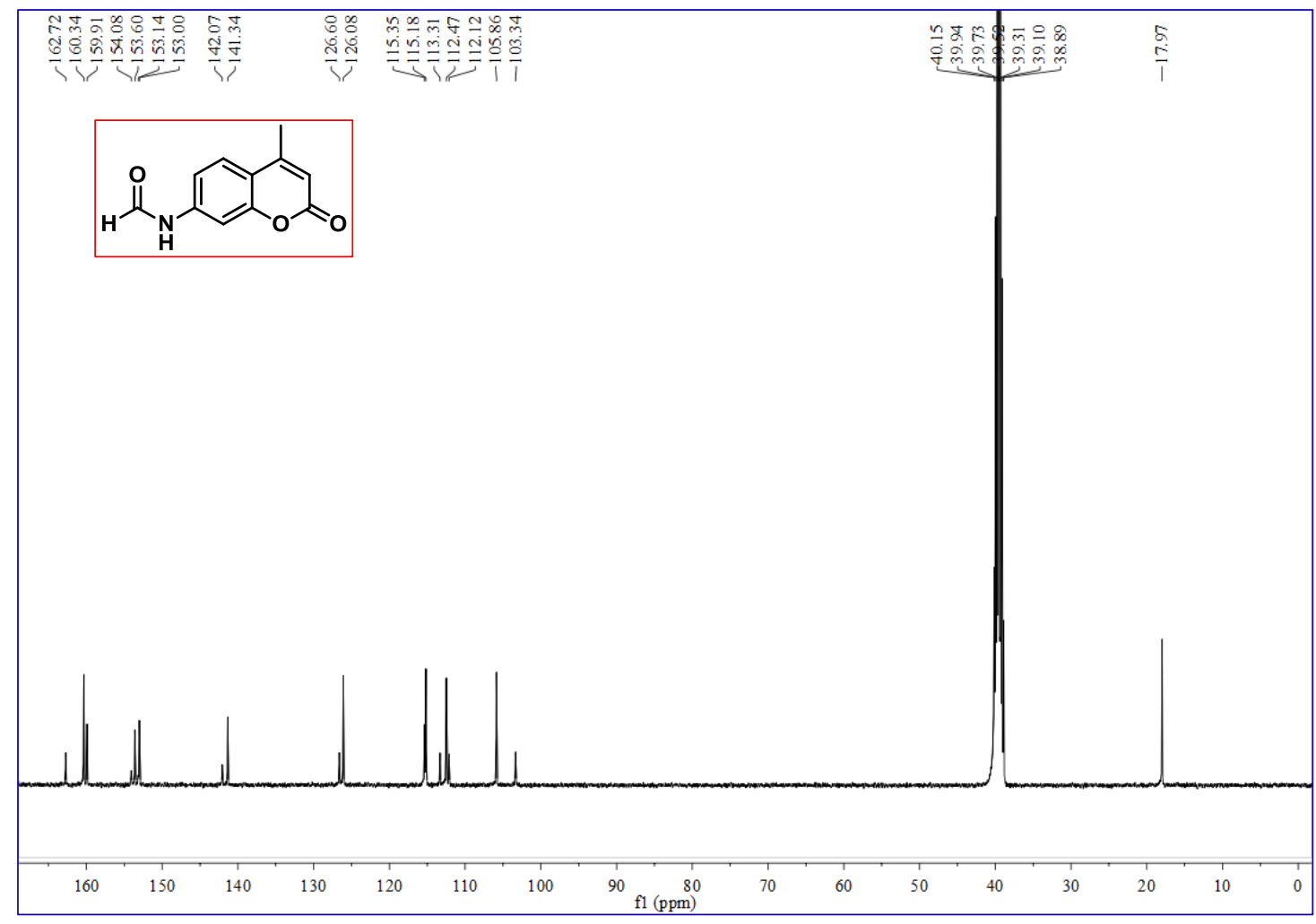

Figure S14. ${ }^{13} \mathrm{C}$ NMR spectrum of FPP-Blue 


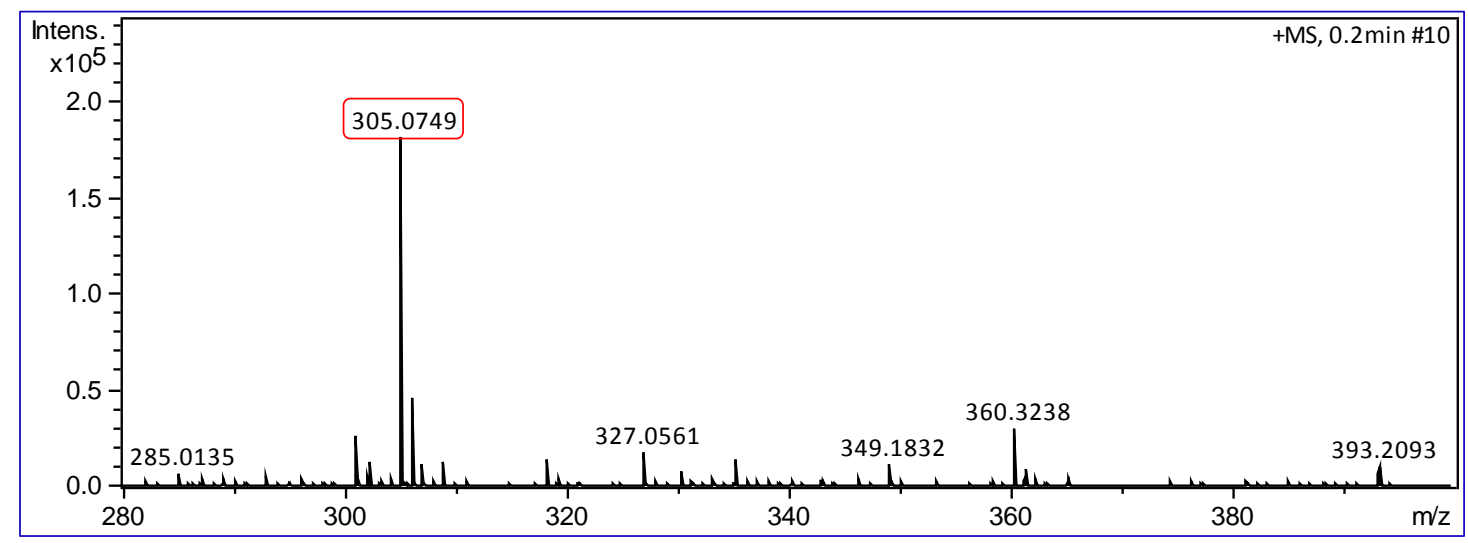

Figure S15. HRMS spectrum of FPP-Green

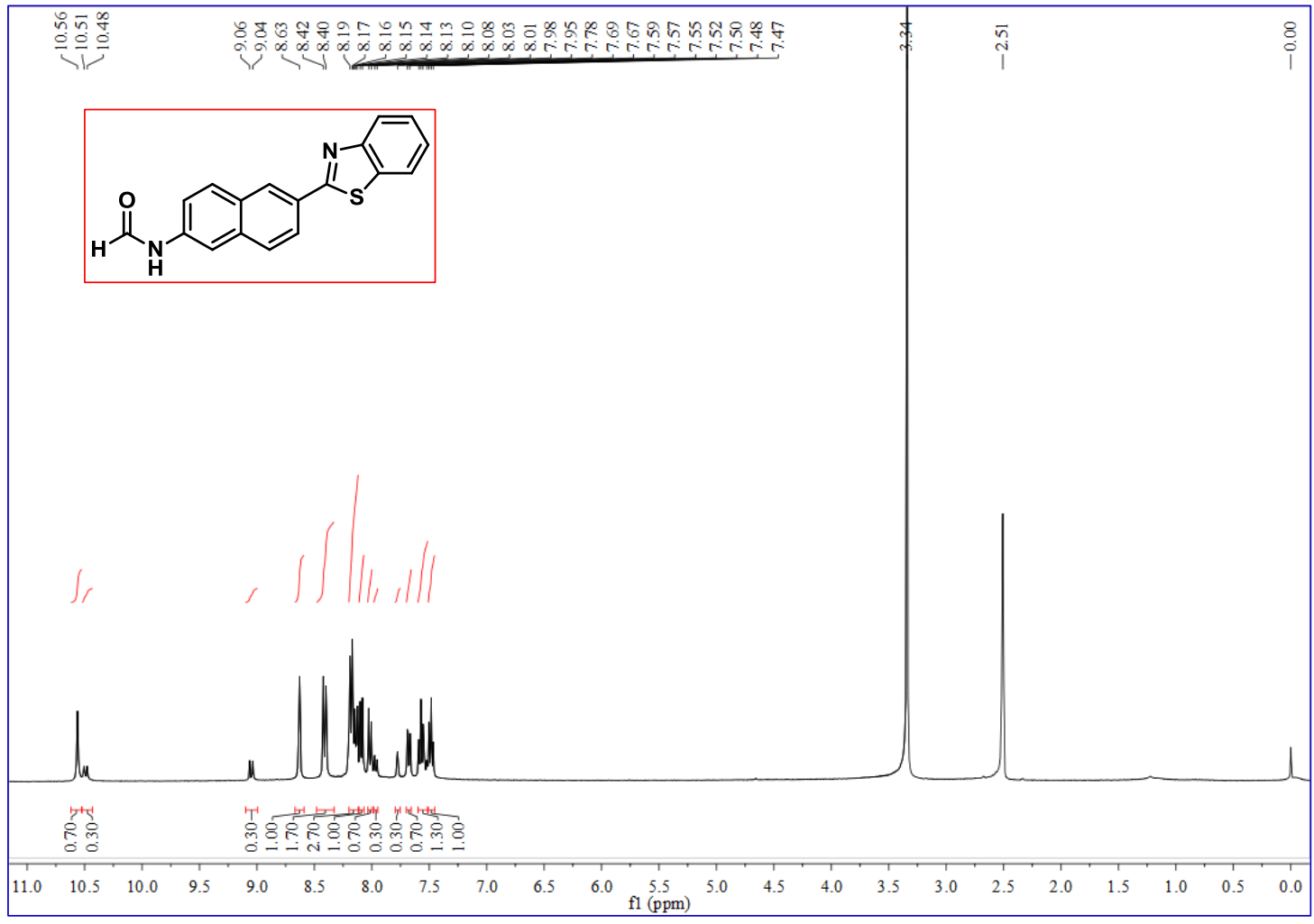

Figure S16. ${ }^{1} \mathrm{H}$ NMR spectrum of FPP-Green 


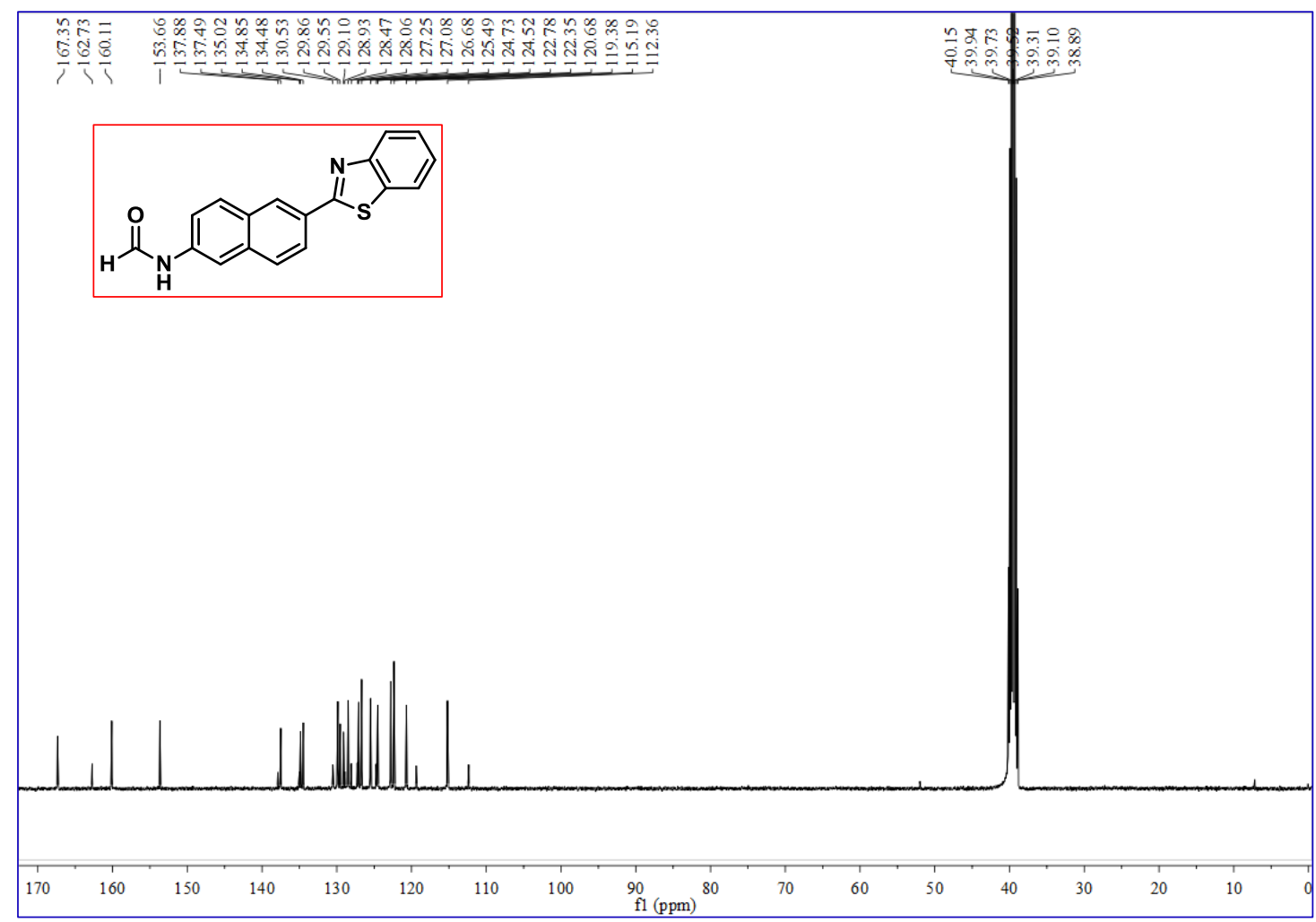

Figure S17. ${ }^{13} \mathrm{C}$ NMR spectrum of FPP-Green

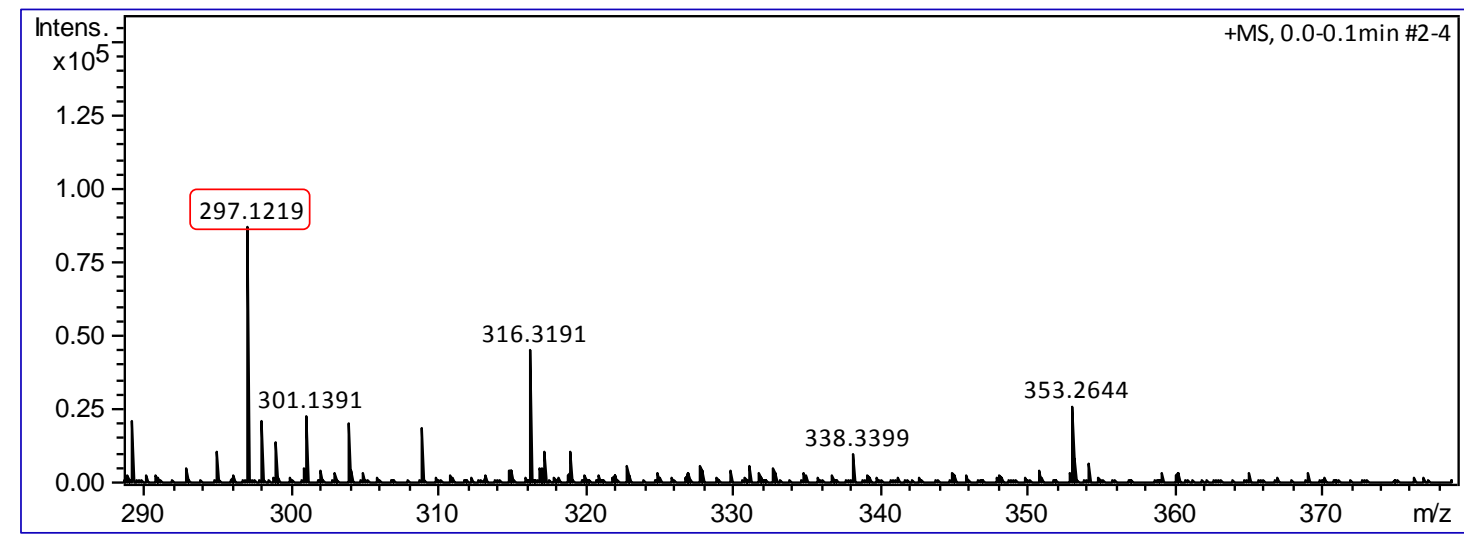

Figure S18. HRMS spectrum of FPP-Yellow 


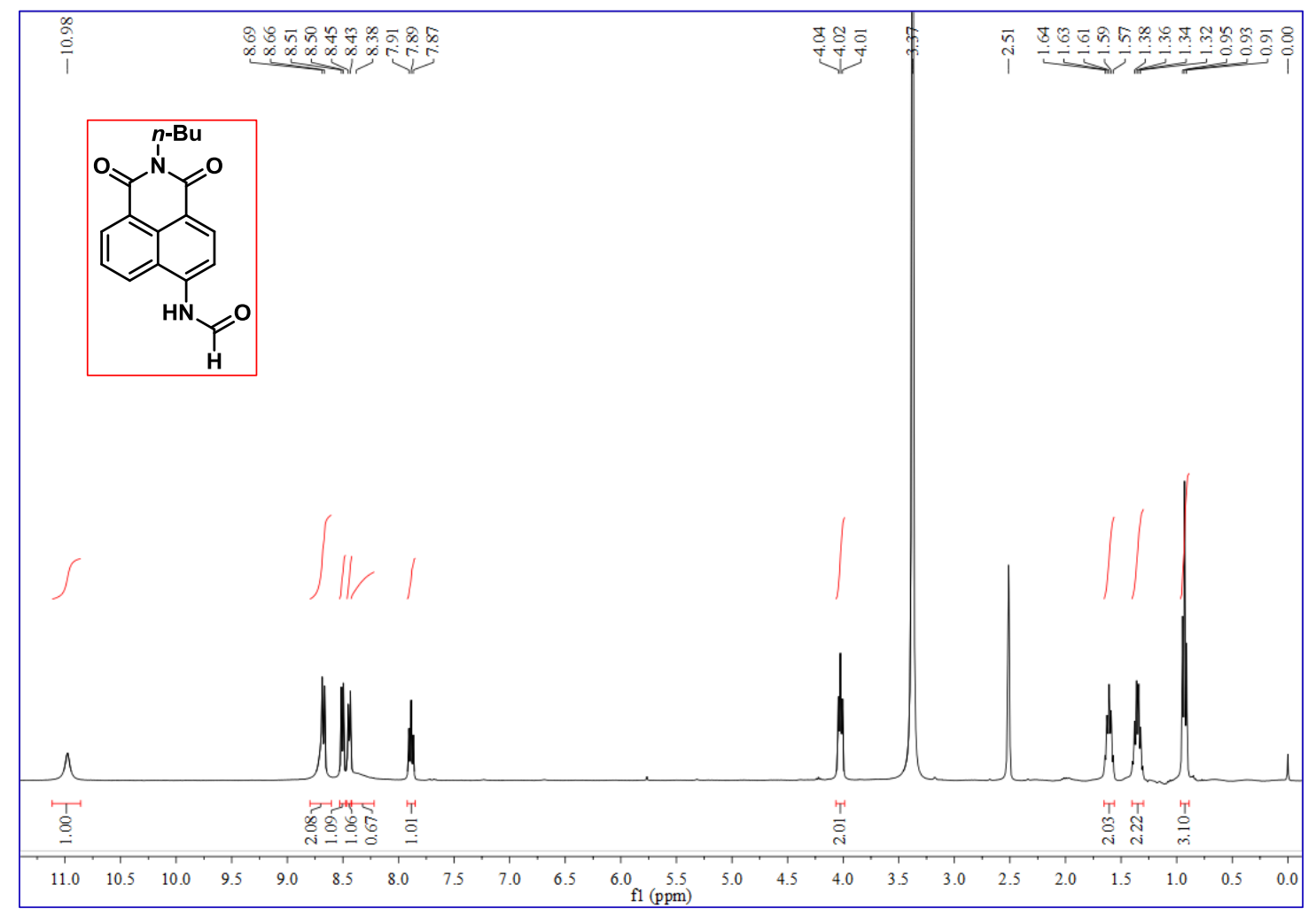

Figure S19. ${ }^{1}$ H NMR spectrum of FPP-Yellow

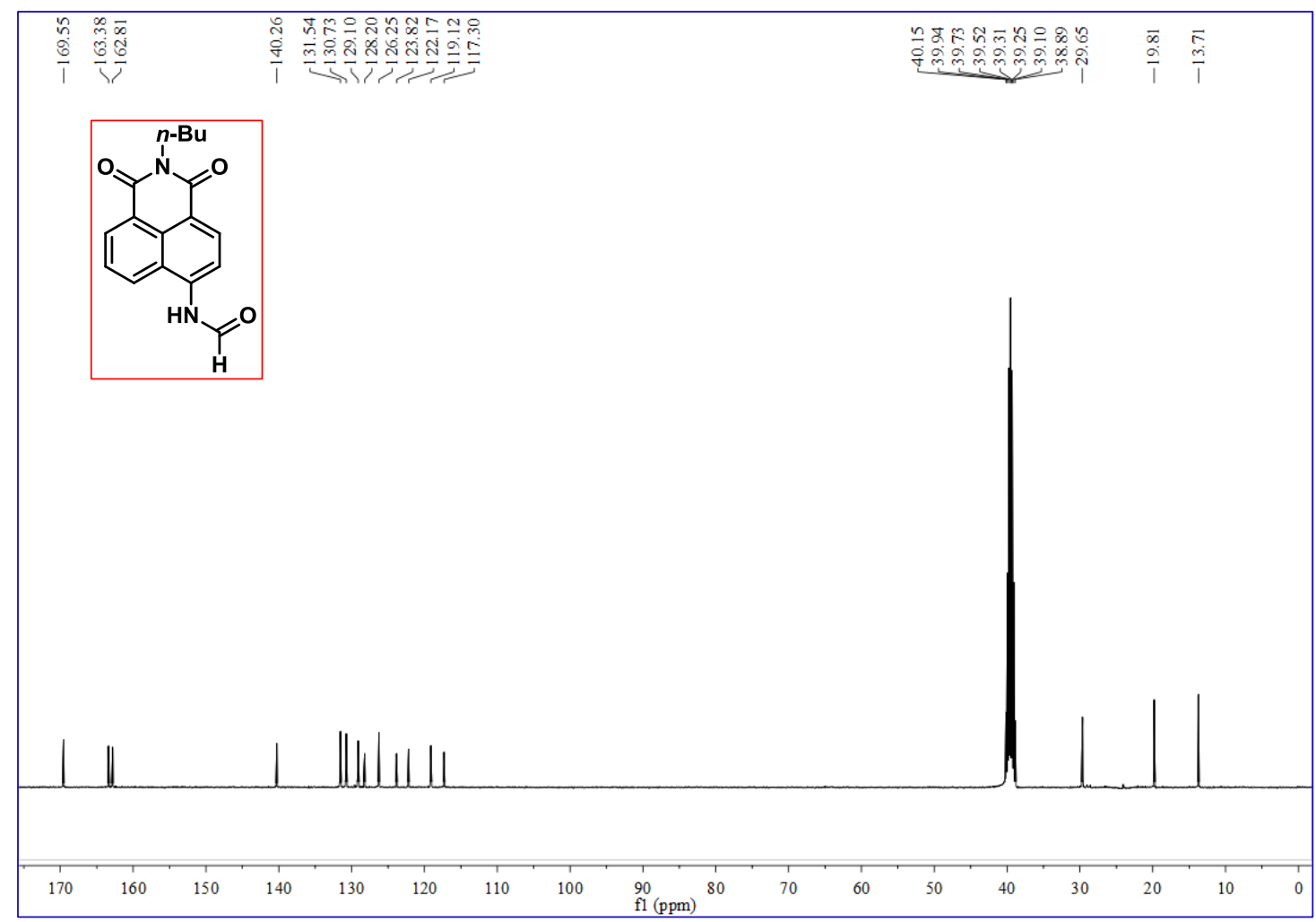

Figure S20. ${ }^{13} \mathrm{C}$ NMR spectrum of FPP-Yellow 


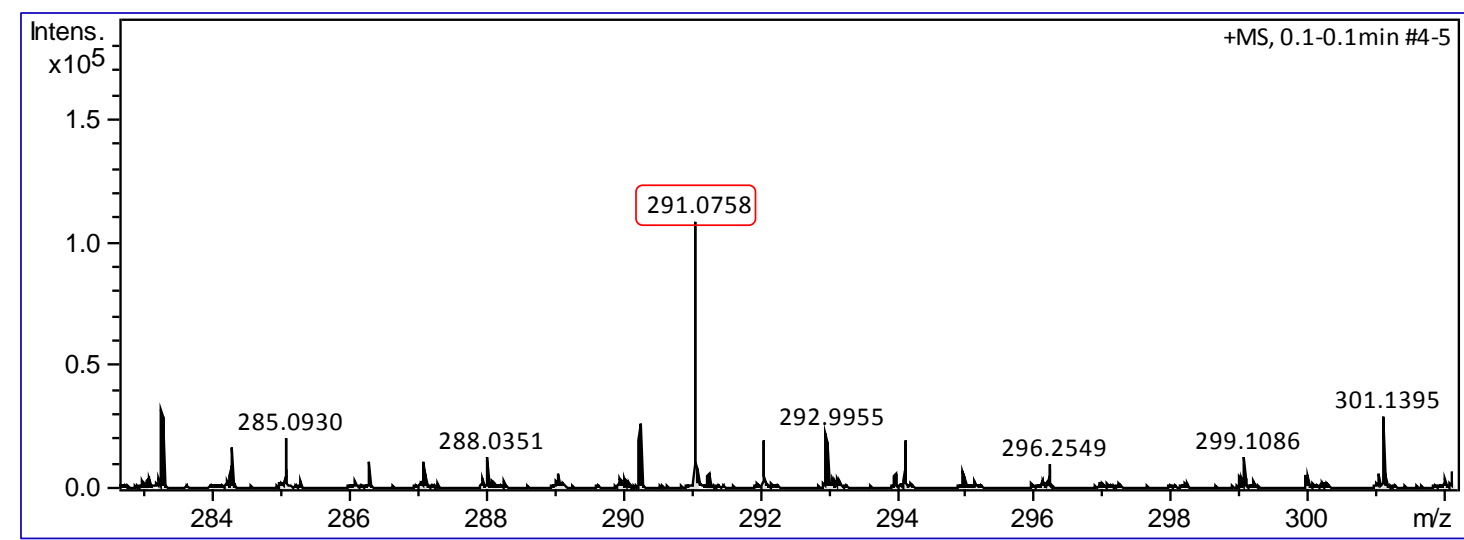

Figure S21. HRMS spectrum of FPP-Red

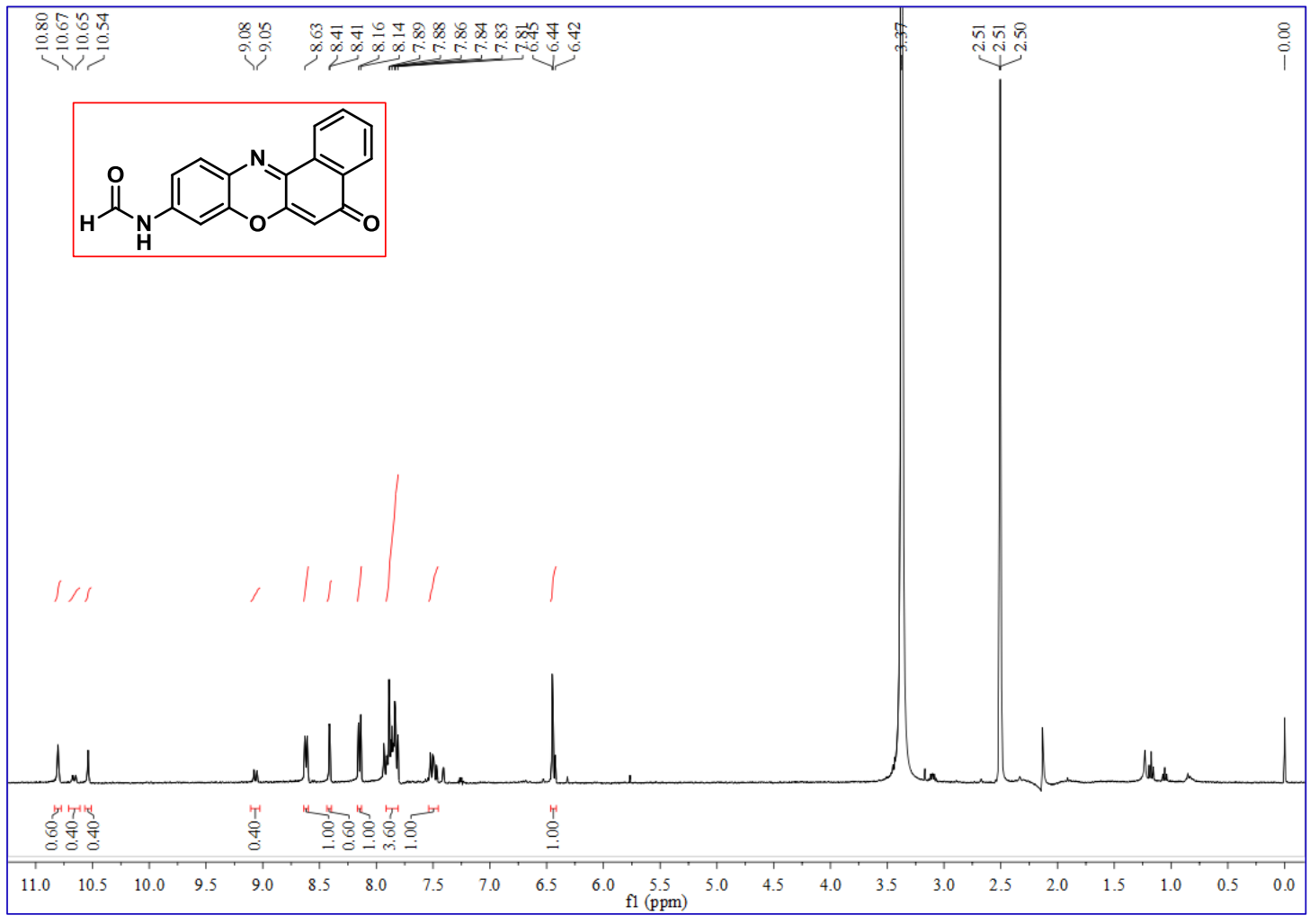

Figure S22. ${ }^{1} \mathrm{H}$ NMR spectrum of FPP-Red 


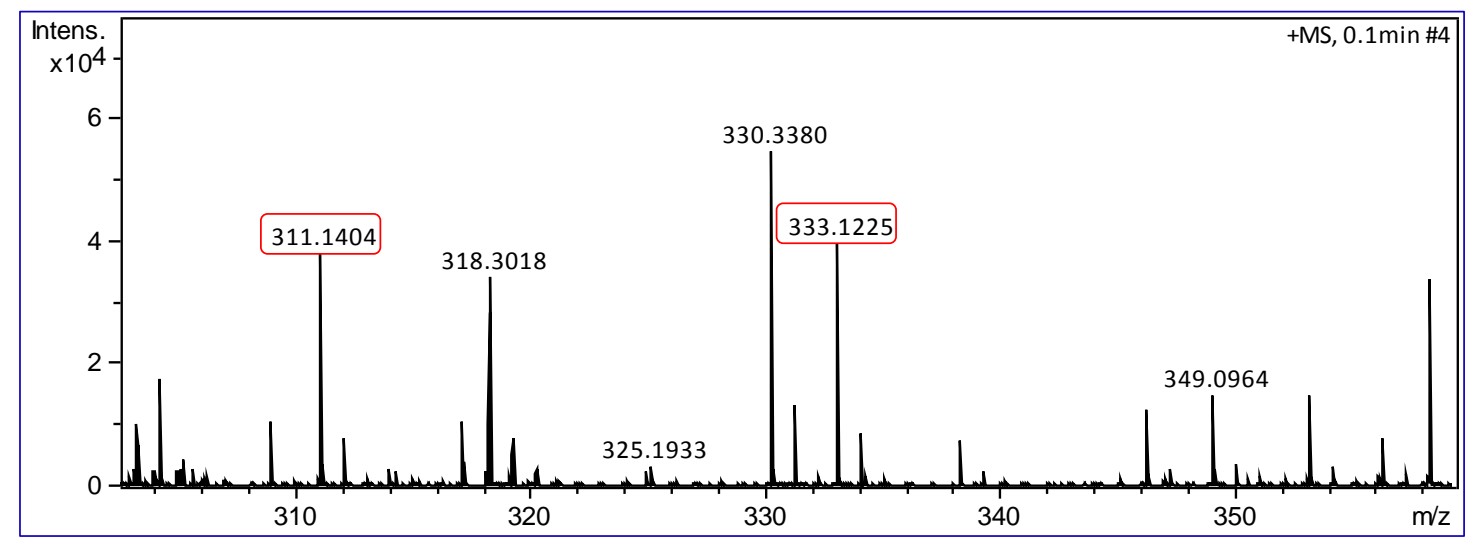

Figure S23. HRMS spectrum of FPP-Ac

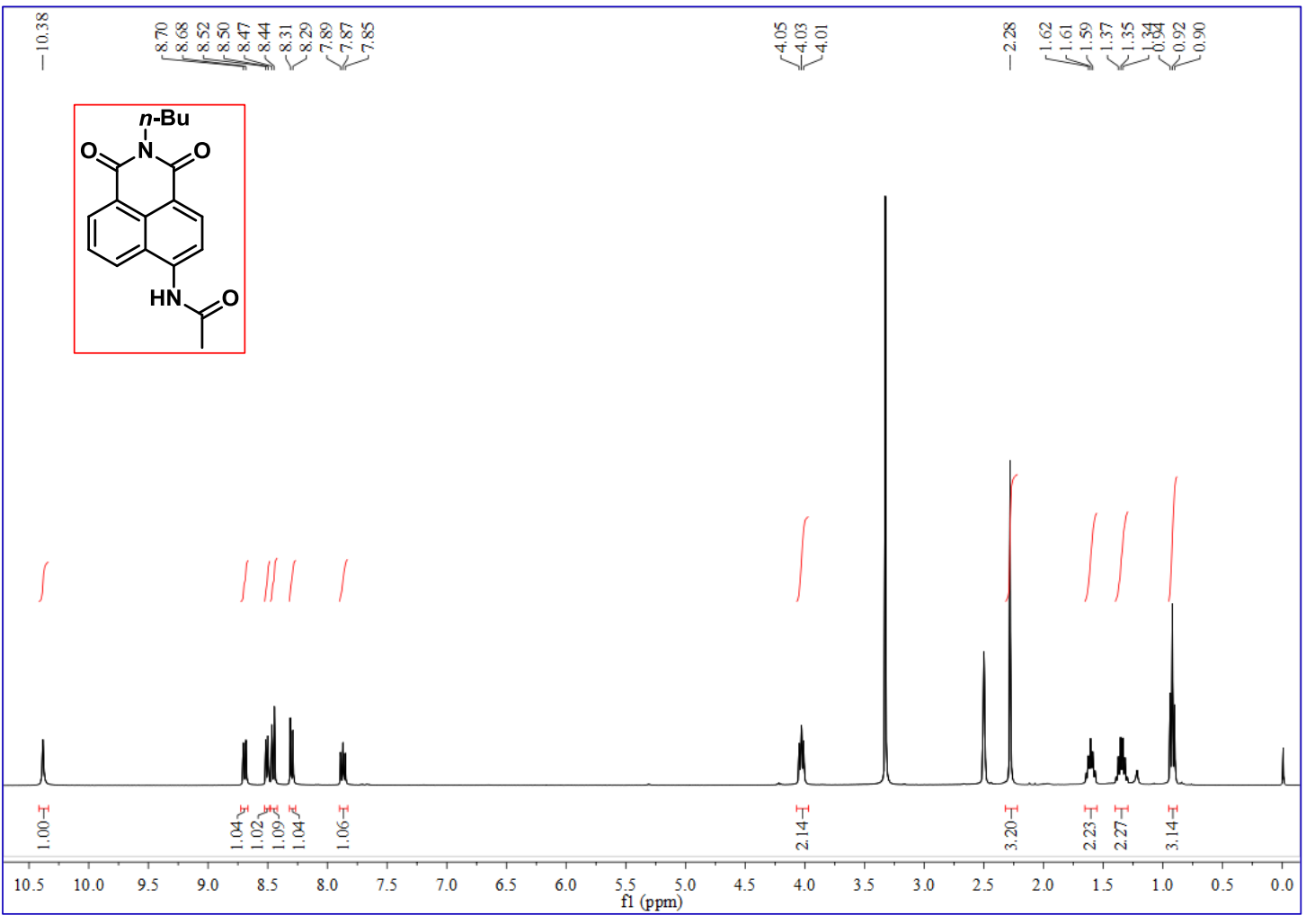

Figure S24. ${ }^{1}$ H NMR spectrum of FPP-Ac 


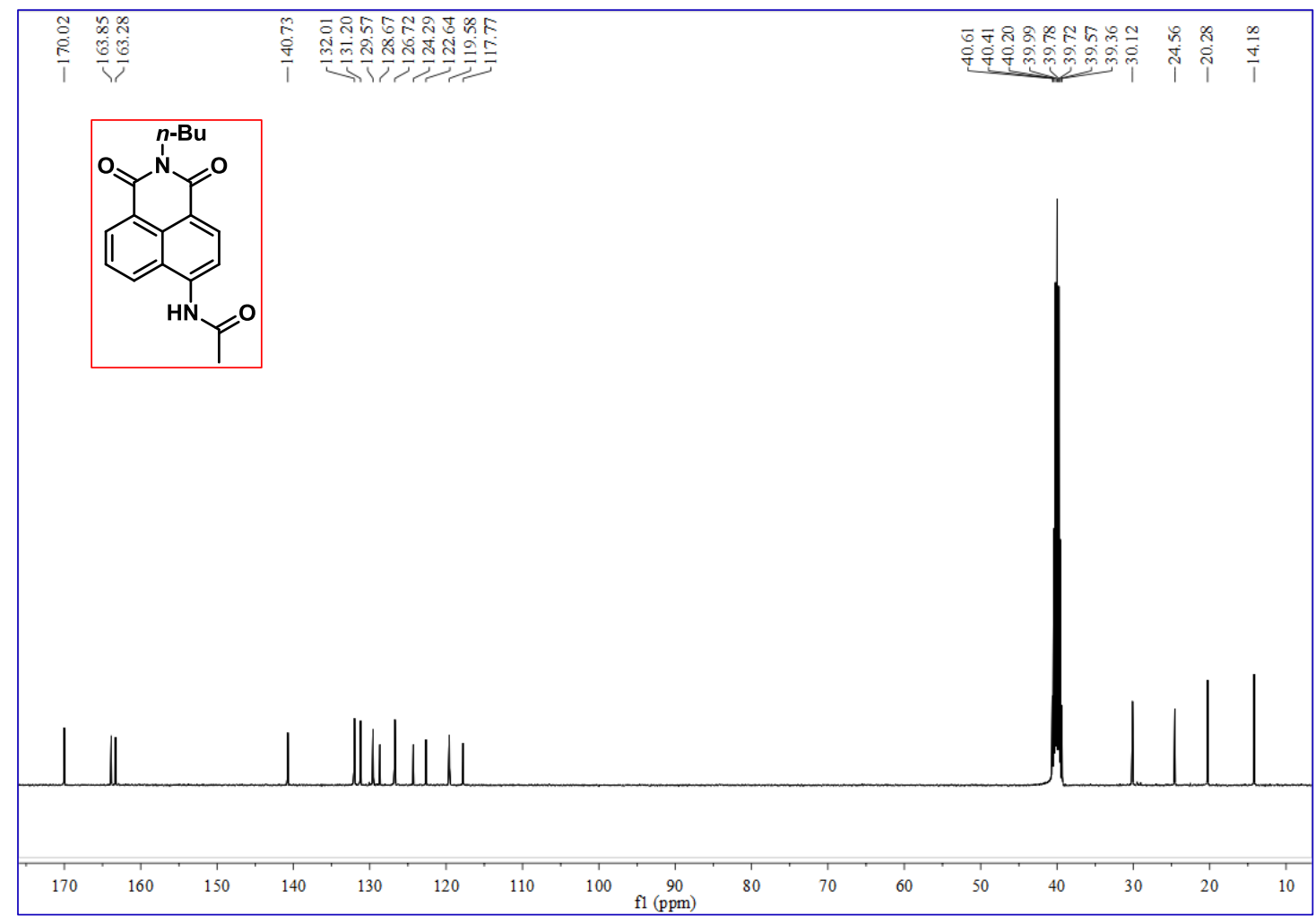

Figure S25. ${ }^{13} \mathrm{C}$ NMR spectrum of FPP-Ac

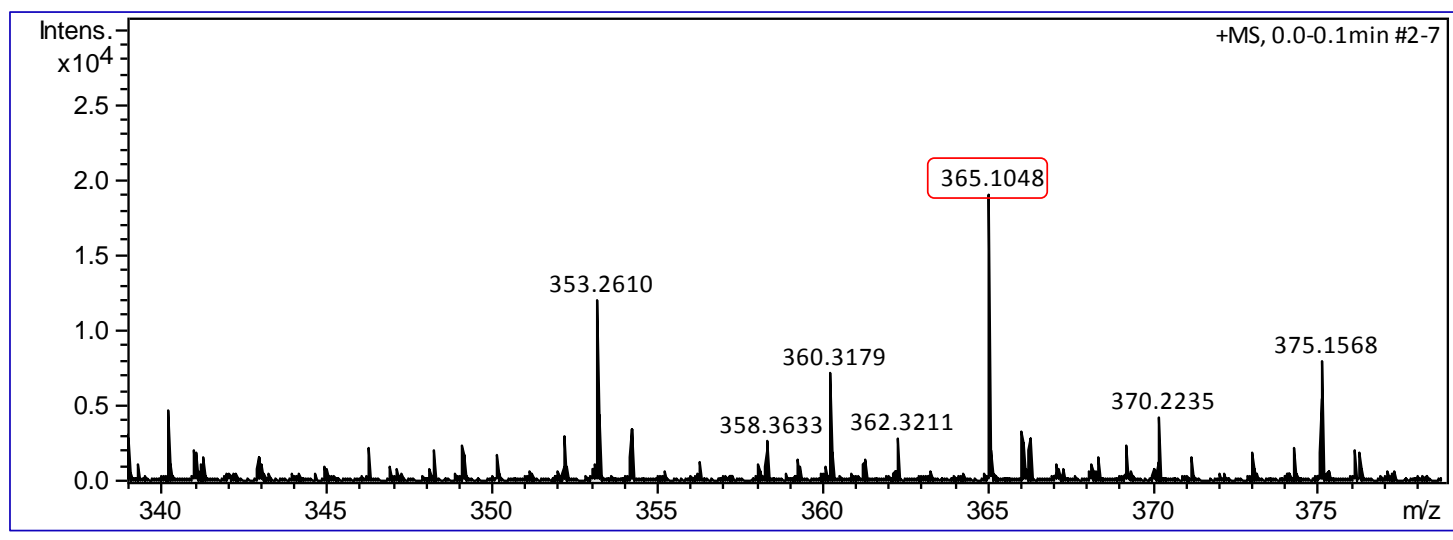

Figure S26. HRMS spectrum of FPP-TFA 


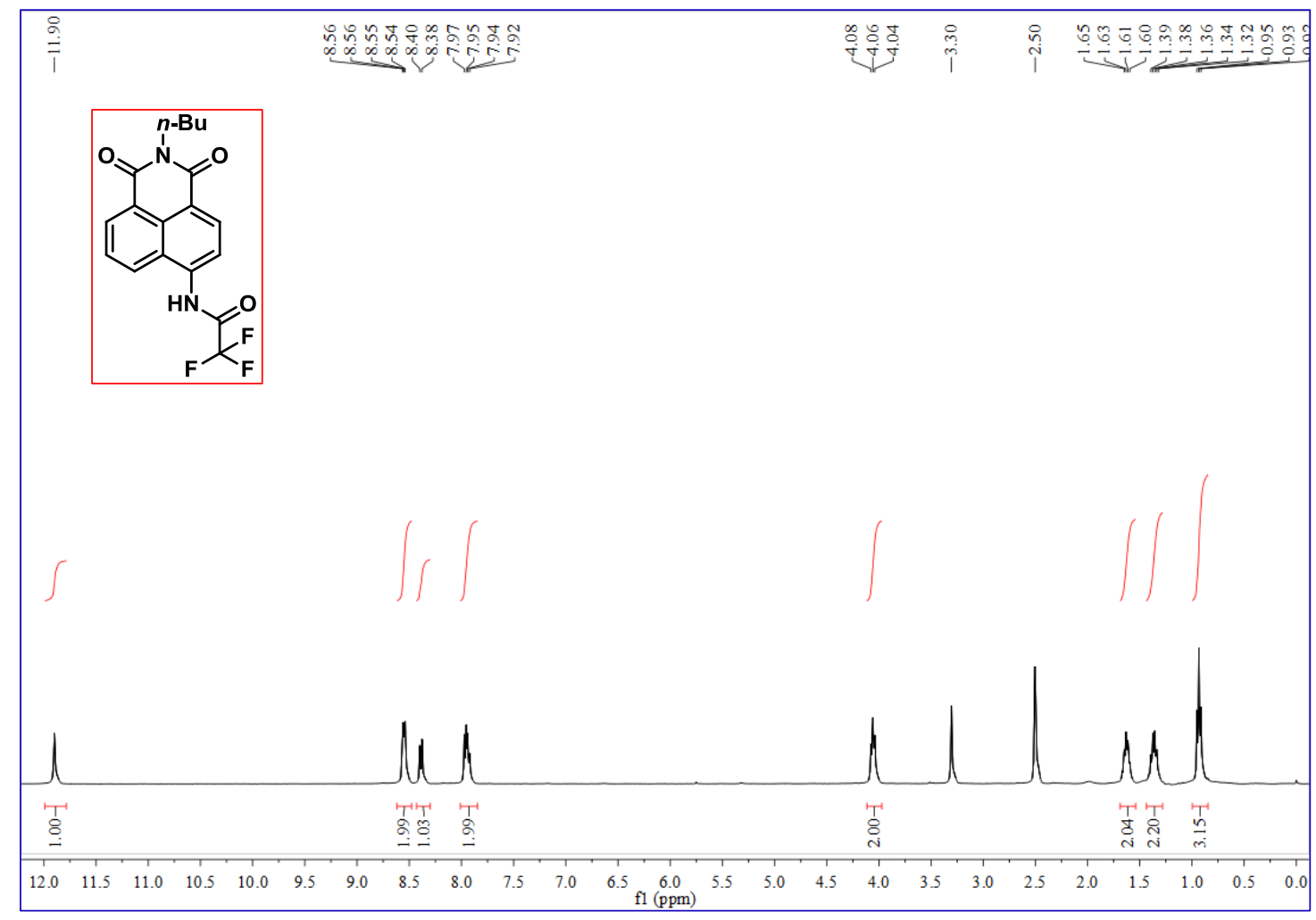

Figure S27. ${ }^{1} \mathrm{H}$ NMR spectrum of FPP-TFA

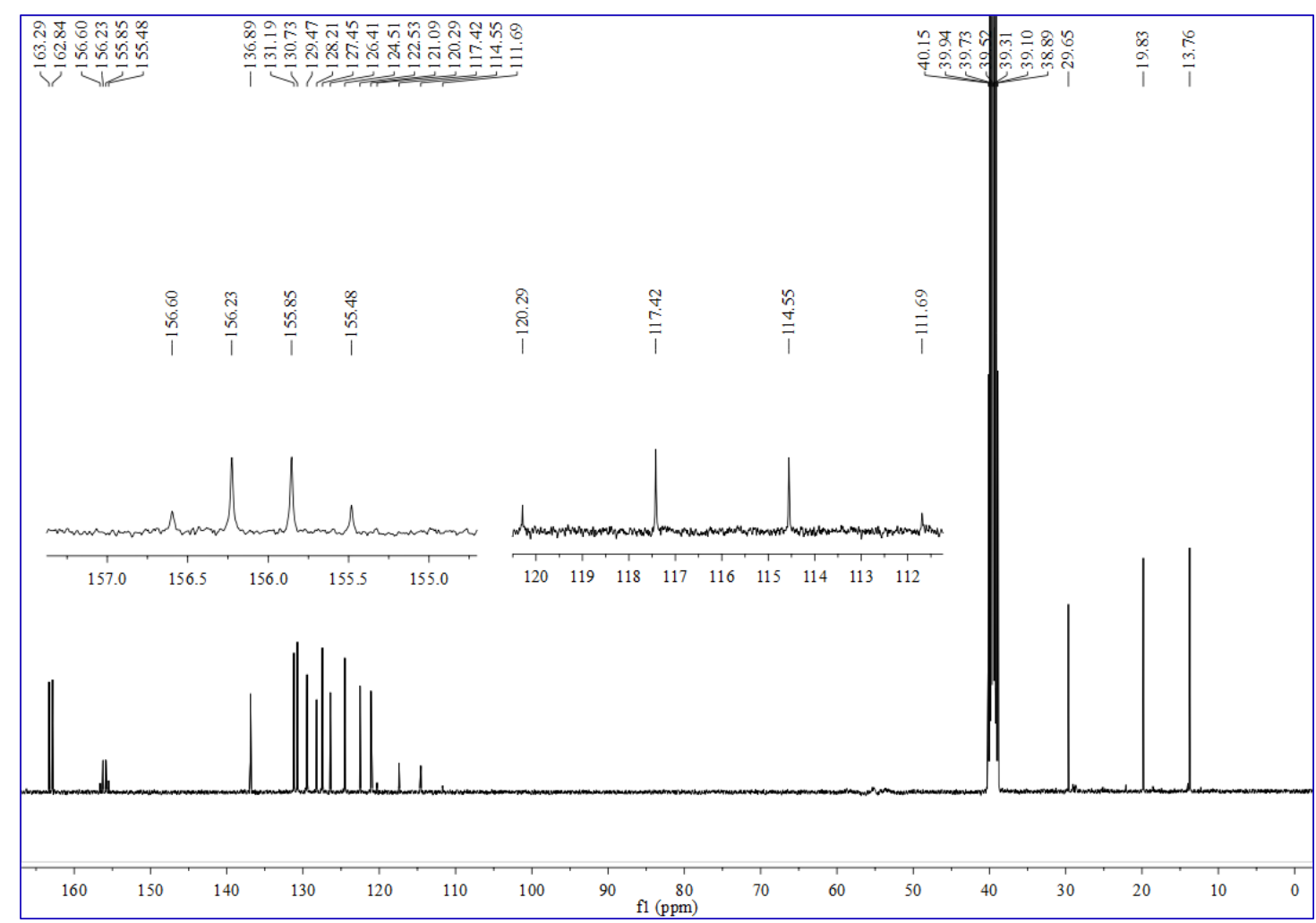

Figure S28. ${ }^{13} \mathrm{C}$ NMR spectrum of FPP-TFA 


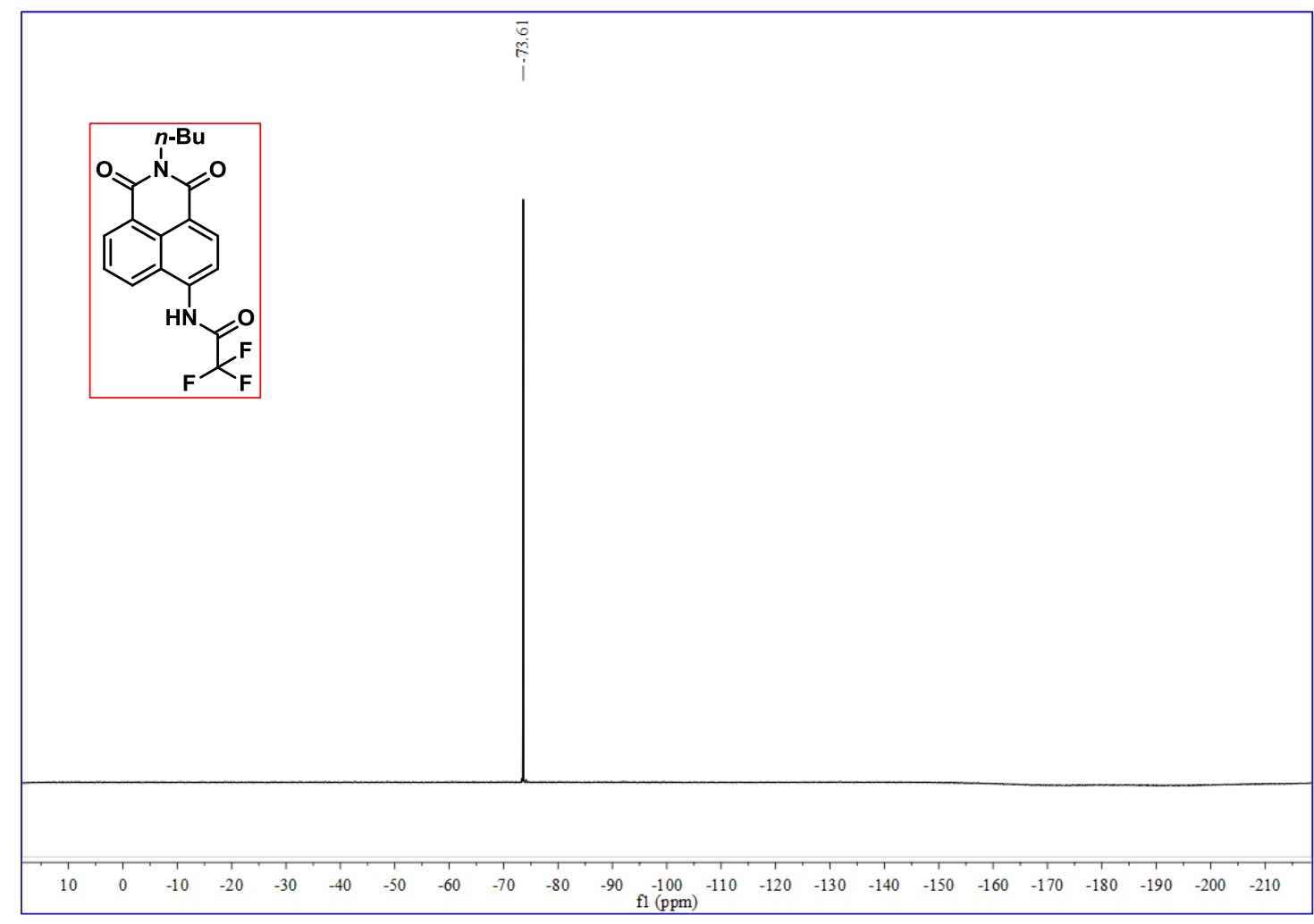

Figure S29. ${ }^{19}$ F NMR spectrum of FPP-TFA 